\title{
Experimental bending tests of partially encased beams at elevated temperatures
}

\author{
Paulo A.G. Piloto a, *, Ana B. Ramos-Gavilán ${ }^{\text {b }}$, Carlos Gonçalves ${ }^{\text {a }}$, Luís M.R. Mesquita ${ }^{\text {a }}$ \\ ${ }^{a}$ LAETA-INEGI, Department of Applied Mechanics, Polytechnic Institute of Bragança, Portugal \\ ${ }^{\mathrm{b}}$ Department of Mechanical Engineering, EPSZ, University of Salamanca, Spain
}

\section{A R T I C L E I N F O}

\section{Keywords:}

Partially encased beams

Composite steel and concrete

Bending resistance

Elevated temperature

Experimental tests

Lateral torsional buckling

\begin{abstract}
A B S T R A C T
This paper presents the result of an experimental research about the lateral torsional buckling instability during bending tests of Partially Encased Beams (PEB) at elevated temperature. A set of twenty seven four-point bending tests, grouped in ten series, were carried out to analyse the influence of relative slenderness, beam temperature and the shear bond conditions between concrete and steel in bending. In addition, this study compares the behaviour of PEB and bare steel beam under bending at room temperature.

PEB specimens are based on IPE100 steel profiles, with two different lengths $2.4 \mathrm{~m}$ (medium series) and $3.9 \mathrm{~m}$ (large series), tested in bending using simple supporting conditions and exposed to different temperatures levels of $200{ }^{\circ} \mathrm{C}, 400{ }^{\circ} \mathrm{C}$, and $600{ }^{\circ} \mathrm{C}$.

Two different shear bond conditions, between steel profile and lateral concrete, were analysed at $400{ }^{\circ} \mathrm{C}$ : one series with connectors formed by welded stirrups to the web and another series with natural adherence between steel and concrete, not welded stirrups.

PEB attained lateral torsional buckling as deformed failure mode at the ultimate limit state, except for the case of PEB tested at $600{ }^{\circ} \mathrm{C}$ that results in a plastic hinge failure. The bending resistance was determined for the maximum load event $\left(\mathrm{F}_{\mathrm{u}}\right)$ and for the displacement limit corresponding to $\mathrm{L} / 30\left(\mathrm{~F}_{\mathrm{L} / 30}\right)$ and compared with the results of the Eurocode 3 part 1-2 simple calculation method, considering an adaptation of its formulae to PEB. The expected reduction in bending resistance at elevated temperature is in good agreement with the experimental reduction factor, when the deformation criterion is used.
\end{abstract}

\section{Introduction}

Partially Encased Beams (PEB) are composite steel and concrete elements in which the web of the steel section is encased by reinforced concrete. PEB have been used in different types of building structures, such as commercial centres, hospitals and hotels. This solution increases the bending and torsional stiffness, and therefore bearing capacity, and improves the fire resistance of steel beams without increasing the overall dimension of the bare steel cross section. The concreting of the beams is done prior to the hoisting and placement, without the need of formwork. The exposed steel surfaces facilitate the joints between them. This solution also improves the seismic behaviour of the bare steel beam, by increasing the stiffness, keeping their ductile behaviour. PEB is an interesting solution for long spans $12-15 \mathrm{~m}$ without additional protection measures, in which reinforced concrete is not viable, and where prestressing may suffer from explosive spalling.
The bending resistance requires full shear connection between the structural steel section and the encased concrete, according to Eurocode 4 part 1-1. The design solution of stirrups welded (W) to the web of the steel profile provides shear connection between the reinforced concrete and the steel profile, and increases concrete confinement. The improvement of the fire resistance of PEB is based on the reduction of the exposed steel surface area to elevated temperatures and the introduction of a low thermal conductivity material (concrete), as verified by the authors [1]. Piloto et al. [1] tested a set of PEB under fire conditions (small series) using three-point bending test, demonstrating the dependence of fire resistance on load level, giving particular emphasis to the critical temperature of this section.

Until this research, only a small number of experiments under fire conditions were reported. In 1987, J. B. Schleich [2] was the project leader of an experimental and numerical campaign developed to test and analyse the behaviour of Partially Encased Columns (PEC) and PEB with

\footnotetext{
* Corresponding author. Campus Santa Apolónia, ap. 1134, 5301-857, Portugal.

E-mail address: ppiloto@ipb.pt (P.A.G. Piloto).
} 


\begin{tabular}{|c|c|c|c|}
\hline \multirow{2}{*}{\multicolumn{2}{|c|}{ Notation and symbols }} & & $\mathrm{z}$ axis \\
\hline & & $I_{z c}$ & Second moment of area of concrete with respect to $\mathrm{z}$ axis \\
\hline & & $L, L_{t}$ & Beam length of the specimen \\
\hline \multicolumn{2}{|c|}{ Latin lower case letters } & $L_{f}$ & Beam length exposed to elevated temperature \\
\hline$a$ & Distance between load and support & $L_{l}$ & Length between loading points \\
\hline$b$ & Width of the profile cross section & $L_{s}$ & Length between supports \\
\hline $\begin{array}{l}b_{1} \\
\bar{b}\end{array}$ & $\begin{array}{l}\text { Width of the encased concrete in the half profile } \\
\text { Average width of the profile specimen }\end{array}$ & $M_{b, f i, t, R d}$ & $\begin{array}{l}\text { Design buckling resistance moment at time } t \text {, under fire } \\
\text { conditions }\end{array}$ \\
\hline$e_{p l}$ & Neutral axis depth at room temperature & $M_{b, R d}$ & Design buckling resistance moment \\
\hline $\begin{array}{l}e_{p l, \theta} \\
e_{r}\end{array}$ & $\begin{array}{l}\text { Neutral axis depth at elevated temperature } \\
\text { Vertical position of reinforcement }\end{array}$ & $M_{b, R k}$ & Characteristic buckling resistance moment to lateral- \\
\hline$f$ & Modification factor & $M_{c r}$ & Elastic critical moment for lateral-torsional buckling \\
\hline$f_{c k}$ & $\begin{array}{l}\text { Characteristic compressive cylinder strength of concrete at } \\
28 \text { days }\end{array}$ & $M_{c r, \theta}$ & $\begin{array}{l}\text { Elastic critical moment for lateral-torsional buckling at } \\
\text { elevated temperature }\end{array}$ \\
\hline$f_{y k}$ & Characteristic value of the yield strength of steel & $M_{b, f i t, R k}$ & Characteristic buckling resistance moment under fire at \\
\hline$f_{s k}$ & Characteristic value of the yield strength of reinforcement & $N_{b, f l, t, R K}$ & time $\mathrm{t}$ \\
\hline$h_{1}$ & depth of the of the encased concrete & $M_{b, f i t, R d}$ & Design buckling resistance moment under fire at time $t$ \\
\hline $\bar{h}$ & Average depth of the profile specimen & $M_{p l, R k}$ & Characteristic value of resistance to bending moment about \\
\hline$k_{c}$ & Correction factor for moment distribution & & $\mathrm{y}$-y axis at room temperature \\
\hline$k_{c, \theta}$ & $\begin{array}{l}\text { Reduction factor of the compressive strength of concrete at } \\
\text { elevated temperature }\end{array}$ & $M_{p l, \theta, R k}$ & $\begin{array}{l}\text { Characteristic value of resistance to bending moment about } \\
y \text {-y axis at elevated temperature }\end{array}$ \\
\hline$k_{s, \theta}$ & $\begin{array}{l}\text { Reduction factor of the reinforcement at elevated } \\
\text { temperature }\end{array}$ & $R_{e H}$ & $\begin{array}{l}\text { Upper yield strength - Maximum value of stress prior to the } \\
\text { first decrease in force during material test, usually consider }\end{array}$ \\
\hline$k_{E, \theta}$ & Reduction factor of the elastic modulus at the steel & & the yield stress \\
\hline$k_{y, \theta}$ & $\begin{array}{l}\text { temperature } \\
\text { Reduction factor for the yield strength of steel at the steel }\end{array}$ & $R_{e L}$ & $\begin{array}{l}\text { Lower yield strength - lowest value of stress during plastic } \\
\text { yielding, ignoring any initial transient effects }\end{array}$ \\
\hline$t_{f}$ & $\begin{array}{l}\text { temperature } \\
\text { flange thickness }\end{array}$ & $R_{m}$ & $\begin{array}{l}\text { Tensile strength - stress corresponding to the maximum } \\
\text { force during material testing }\end{array}$ \\
\hline $\begin{array}{l}\bar{t}_{f} \\
t_{w}\end{array}$ & $\begin{array}{l}\text { Average flange thickness of the profile specimen } \\
\text { web thickness }\end{array}$ & $R_{p .0 .2 \%}$ & $\begin{array}{l}\text { Strength of steel corresponding to } 0.2 \% \text { strain during } \\
\text { material test }\end{array}$ \\
\hline $\bar{t}_{w}$ & Average web thickness of the profile specimen & $T s_{i}$ & Average temperature of the section $\mathrm{Si}$ weighted to the area \\
\hline$y_{r}$ & Horizontal position of reinforcement & $W_{p l y}$ & Plastic section modulus of steel profile about $y-y$ axis \\
\hline Latin up & er case scalars & $\bar{X}_{F_{i}}$ & Average value of the force type i \\
\hline$A_{r}, A_{s}$ & Cross sectional area of reinforcement & $Y_{G}$ & Lateral displacement of the centre of gravity of the \\
\hline$A_{t}$ & $\begin{array}{l}\text { Percentage total extension at fracture - total extension at } \\
\text { the moment of fracture, during material testing }\end{array}$ & $Z_{G}$ & $\begin{array}{l}\text { PEB section } \\
\text { Vertical displacement of the centre of gravity of the }\end{array}$ \\
\hline$E_{a, \theta}, E_{s, \theta}$ & Elastic modulus of steel at elevated temperature & & \\
\hline$E_{s}, E_{a}$ & Elastic modulus of steel & Scalar lov & ver case letter using Greek symbols \\
\hline$E_{c}$ & Elastic modulus of concrete & $\alpha$ & Imperfection factor under fire conditions \\
\hline$E_{c, \theta}$ & Elastic modulus of concrete at elevated temperature & $\alpha_{L T}$ & The imperfection factor \\
\hline$E_{s, \theta}$ & $\begin{array}{l}\text { Elastic modulus of the reinforcement at elevated } \\
\text { temperature }\end{array}$ & $\beta$ & $\begin{array}{l}\text { Value to determine the reduction factor for lateral- } \\
\text { torsional buckling }\end{array}$ \\
\hline$F_{L / 30}$ & $\begin{array}{l}\text { Force corresponding to a vertical displacement of } \mathrm{L} / 30 \text { at } \\
\text { mid span }\end{array}$ & $\begin{array}{l}\varepsilon \\
\varepsilon_{y}\end{array}$ & $\begin{array}{l}\text { Axial strain measurement } \\
\text { Axial strain corresponding to yielding of the steel profile }\end{array}$ \\
\hline$F_{M p l}$ & Force corresponding to the plastic moment of the & $\bar{\lambda}_{L T}$ & Non dimensional slenderness for lateral-torsional buckling \\
\hline$F_{p}$ & $\begin{array}{l}\text { cross section } \\
\text { Force corresponding to proportional limit of the specimen }\end{array}$ & $\bar{\lambda}_{L T, 0}$ & $\begin{array}{l}\text { Plateau length of the lateral-torsional buckling curves for } \\
\text { rolled sections }\end{array}$ \\
\hline $\begin{array}{l}F_{u} \\
F_{y}\end{array}$ & $\begin{array}{l}\text { Maximum force applied to the specimen during test } \\
\text { Force corresponding to yielding of the specimen }\end{array}$ & $\bar{\lambda}_{L T, \theta, c o m}$ & Non dimensional slenderness for lateral-torsional buckling \\
\hline$G_{s}, G_{a}$ & Shear modulus of the steel & $y_{I T}$ & factor \\
\hline$G_{a, \theta}$ & Shear modulus of steel at elevated temperature & ${ }^{L} T$ & torsional buckling \\
\hline$G_{c}$ & Shear modulus of concrete & $\Phi_{L T, \theta, c o m}$ & Value to determine the reduction factor for lateral-torsional \\
\hline$G_{c, \theta}$ & Shear modulus of concrete at elevated temperature & & buckling at the temperature of the compressed fibre \\
\hline$I_{t}$ & Torsion constant of PEB section & $\chi_{L T}$ & Reduction factor for lateral-torsional buckling \\
\hline$I_{t, c}$ & Torsion constant of concrete & $\chi_{L T, f i}$ & Reduction factor for lateral-torsional buckling in the fire \\
\hline$I_{t, s}$ & Torsion constant of the steel profile & & design situation \\
\hline & Warping constant of the homogenised section & $\chi_{L T, \bmod }$ & Modified reduction factor for lateral-torsional buckling \\
\hline $\begin{array}{l}I_{w, a} \\
I_{y}, I_{z}\end{array}$ & $\begin{array}{l}\text { Second moment of area of the homogenised section with } \\
\text { respect to both axes }\end{array}$ & $\chi_{L T, f i, \bmod }$ & $\begin{array}{l}\text { Modified reduction factor for lateral-torsional buckling at } \\
\text { elevated temperature }\end{array}$ \\
\hline$I_{z a}$ & $I_{z s}$ Second moment of area of the steel profile with respect to & & \\
\hline
\end{tabular}


and without connection to the slab. This project demonstrated the ability of the computer code CEFICOSS to cover most structural fire applications. Karl Kordina [3] presented tables with minimum dimensions to be used in the fire design of composite columns, including PEC, based on experiments. These results were verified in PEC and PEB, for different degrees of utilization, supporting conditions and materials. Kindmean et al. [4], performed thirteen tests on PEB with and without concrete slabs, showing the importance of the reinforced concrete between flanges for the ultimate bending moment. This research caused the revision of Eurocode 4 (pre-standard) for the design of partially encased composite beams to include the encased material contribution in the load bearing resistance and deflection. Hosser et al. [5], carried out four experimental tests on simply supported composite PEB connected to reinforced concrete slabs under fire conditions. Temperature evolution was registered at different locations, including in the PEB cross section. The authors also presented results from finite element analysis, concluding that the effective width of the slab depends on the transversal longitudinal shear reinforcement. Lindner et al. [6] investigated the lateral instability of PEB at room temperature using two different steel sections, introducing a new design proposal to lateral torsional buckling, taking into consideration the torsional stiffness of concrete. Maquoi et al. [7], worked on lateral torsional buckling of PEB and improved design rules that were not well covered by the existing standards, using experimental tests with numerical validation, revising and improving the elastic critical moment and the ultimate lateral torsional buckling moment. Assi et al. [8], developed a theoretical background and an experimental study on the ultimate moment capacity of PEB, performing twelve bending tests on specimens with four different IPE cross sections. They studied the contribution of different types of concrete and concluded that encasement of concrete significantly enhances the load carrying capacity of bare steel sections. Makamura et al. [9], tested three Partially Encased Girders (PEG) with longitudinal and transversal rebars (welded and not welded to flanges), showing that the bending strength of the PEG was almost two times higher than conventional bare steel girders and that the specimen with rebar not welded to flanges presented a decrease of $15 \%$ for maximum load bearing when compared to the one with welded rebars. More recently, Kodaira et al. [10], determined the fire resistance of eight $\mathrm{PEB}$, with and without concrete slabs, demonstrating that the reinforcement is effective during a fire. In 2008, Elghazouli et. Al. [11] performed ten full scale tests on $\mathrm{PEB}$, assessing the inelastic performance and discussing several parameters (strain hardening of steel, concrete confinement, extension of section yielding) related to capacity and ductility with relevance to design. Nardin and El Debs [12], studied the static behaviour of three composite PEB under flexural loading at room temperature, testing some alternative positions for shear studs, confirming that studs are responsible for the composite action and for increasing the bending strength. Authors also presented a new analytical method to estimate the bending capacity of PEB.

According to EN1994-1-2 [13], the bending resistance under fire can be determined by tabulated data, by a simple calculation method or by an advanced calculation method. Tabulated method can only be used for beams with simple supported conditions exposed to standard fire. The simple calculation method, for the design of composite beams, is only applied to simple support conditions and standard fire exposure from three sides, and takes into account the reduction of dimensions of the parts composing the cross section (geometry) and the reduction of the mechanical properties of materials, to represent the effect of temperature on material characteristics, without considering lateral torsional buckling as deformed failure mode. This method may be applied to PEB, assuming no mechanical resistance of the concrete slab. Advanced calculation method can also be used to calculate bending resistance at elevated temperatures through an uncoupled thermal and mechanical analysis. Test results may also be used to assess the fire behaviour of structural members, sub-assemblies or entire structures if they come from tests adequately performed.

The experimental study presented herein aims to analyse the lateral torsional buckling resistance of PEB at elevated temperature by means of four-point bending tests. Specimens were heated between loading points, from two sides (top and bottom flanges) and load was increased step by step, after stabilizing the temperature of the test $\left(200{ }^{\circ} \mathrm{C}, 400{ }^{\circ} \mathrm{C}\right.$, and $600^{\circ} \mathrm{C}$ ). The experimental tests were defined to be developed at constant temperature level with increasing mechanical load. This purpose helps to verify or suggest prescriptive designing formulas and guarantees that failure is achieved at specific temperature level (not before or after maximum temperature level, as could be the case of natural fire). The test set-up was conceived to approximate the load of the specimen to an almost constant bending moment, being the results only valid to this load and support condition, either PEB is considered as main or secondary beam. Lateral torsional buckling should be consider a potential failure mode at room and elevated temperature for unrestrained PEB, when compressive stresses are responsible for the existing of an out-of-plane bending moment and lateral displacement. The bending resistance of PEB is also compared with bare steel beams at room temperature. Two different beam lengths were considered (medium and large series), using one type of cross section (IPE100). Two different shear bond conditions between concrete and steel profile were analysed at $400{ }^{\circ} \mathrm{C}$ : with connectors formed by stirrups welded to the web profile and with natural adherence without welded stirrups.

This research allows to determine the lateral torsional buckling resistance of PEB at elevated temperatures, to propose an adaptation of the simple calculation method from EN1993 1-2 [14] to composite steel and concrete structures. This investigation also demonstrates that lateral torsional buckling is a potential failure mode to be consider in partially encased beams under fire conditions, especially when these elements are not connected to the slab. This research also provides data to calibrate and validate the new simple calculation method and advanced calculation method.

\section{Specimens and loading conditions}

Specimens are formed by hot rolled profile IPE100 with steel grade S275, laterally encased by reinforced concrete C20. The longitudinal reinforcement consists of four rebars of steel B500 with $8 \mathrm{~mm}$ on diameter. The transversal reinforcement is formed by open stirrups of steel rebars B500 with the diameter of $6 \mathrm{~mm}$, spaced every $167 \mathrm{~mm}$ in longitudinal direction. IPE 100 steel bare section is classified as class 1 , with depth width ratio of 1.8. The non-dimensional slenderness of bare steel beams to be tested are between 1.0 and 1.4, at room temperature, which enhances lateral torsional buckling as a potential mode of instability. This cross section was elected to prone beam to a global instability mode, minimizing the difficulties associated with experimental tests. The conclusions of this investigation are applied only to this composite section, due to the limited number of tests developed on PEB.

Two different shear condition between concrete and steel were used: with stirrups welded to the web (W) and non-welded stirrups (NW), both represented in Fig. 1. According to EN1994-1-1 [15], this composite steel and concrete section is classified as class 1 .

Stirrups were also partially welded to the longitudinal steel reinforcement, as represented in Fig. 1.

The plastic neutral axis is referenced to "epl", being the reinforced concrete block dimensions represented by "b1" and "h1", while "er" and "yr" represent the relative position for longitudinal reinforcement.

Specimens were tested using a steel portal frame, see Fig. 2, using two fork supports (restraining axial rotation, lateral and vertical displacement) and two-point load (restraining axial rotation but allowing for lateral displacement). Room temperature tests were developed in one single stage, using small increments of displacement $(2.4 \mathrm{~mm} / \mathrm{min})$, while elevated temperature tests were developed in two stages. The first stage was used for heating the beam along the length exposed to high temperature "Lf", using a constant heating rate and a dwell time for constant temperature. During the second stage, temperature was kept constant and load was applied using small increments of displacement 


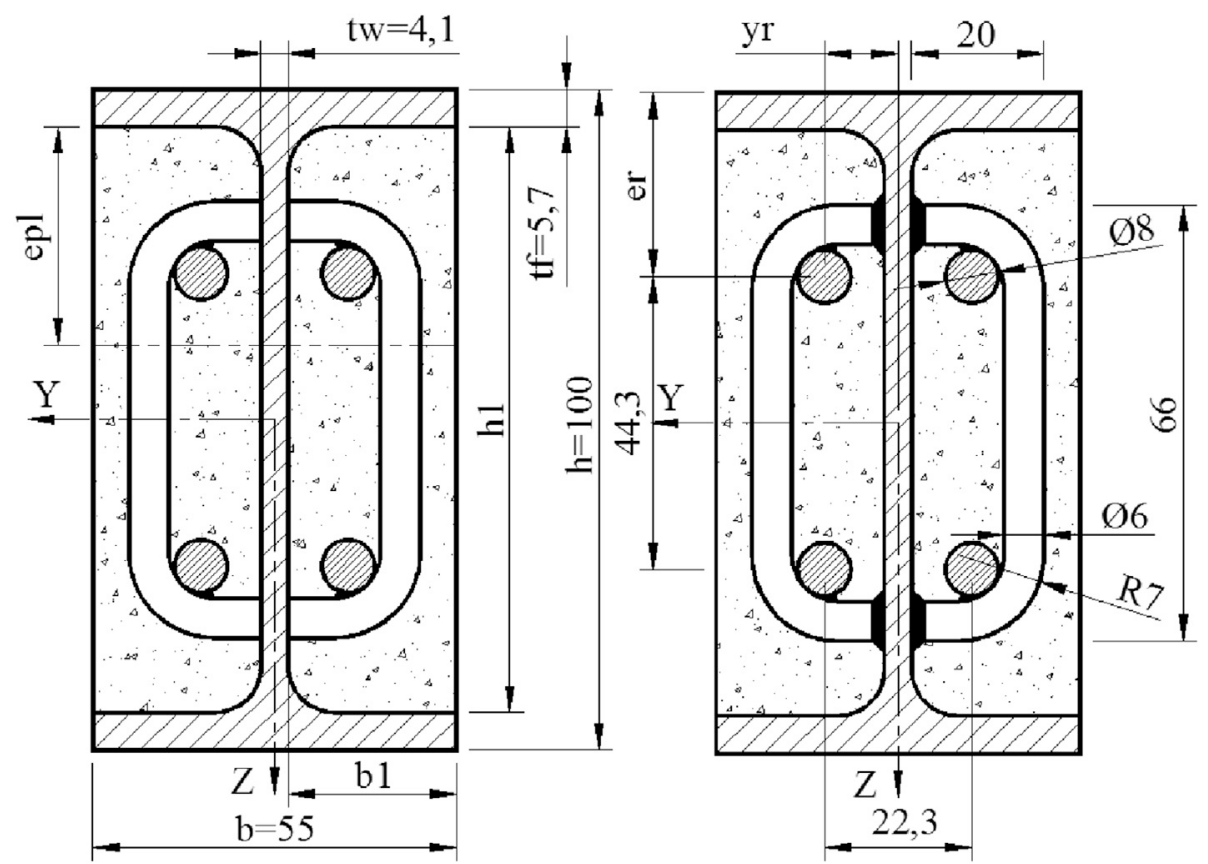

Fig. 1. Nominal cross section dimensions of PEB with welded stirrups (W) on the right and not welded (NW) on the left (units in mm).

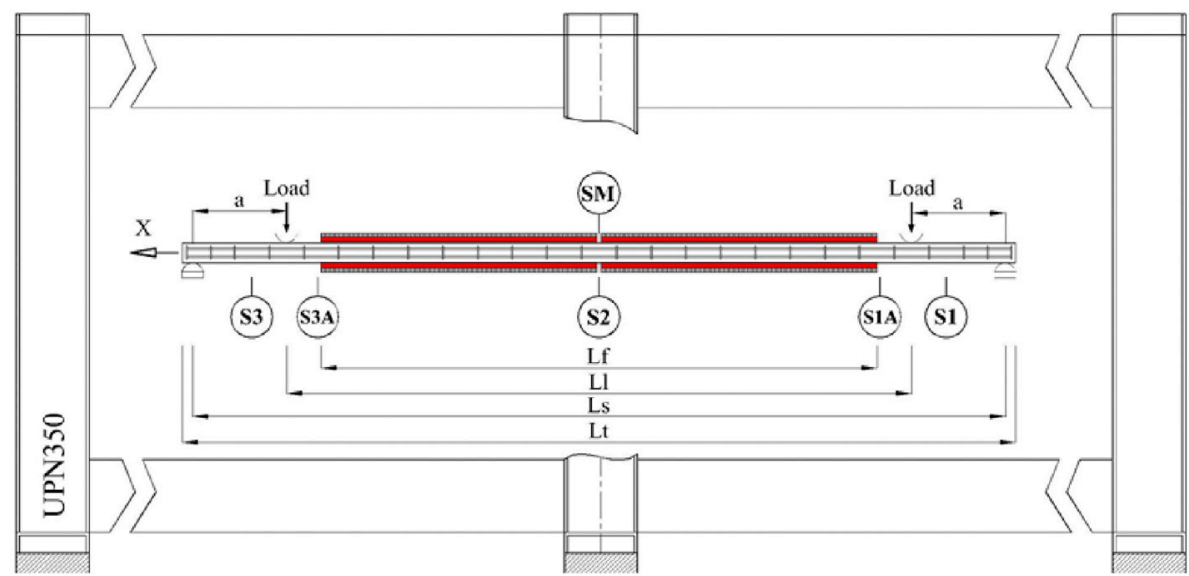

Fig. 2. Testing conditions and identification of the main cross sections.

$(2.4 \mathrm{~mm} / \mathrm{min})$ until the attainment of the ultimate limit state. This investigation aims to test PEB at almost constant temperature level using incremental load. This setup will provide a set of bending resistance (load domain) for a set of temperature levels. Four different load events were identified during tests to characterize the limit of proportionality between load and vertical displacement, the yielding of the cross section, the maximum load recorded and the load corresponding to L/30.

\section{Bending resistance of PEB - simple calculation method}

Experimental bending resistance of PEB at room and elevated temperature was compared with the plastic resistance moment of the composite section using the characteristic material properties. The plastic resistance moment of PEB was calculated in accordance with EN 1994-11 [15], which assumes that: there is full interaction between structural steel and concrete; the effective area of the steel profile is stressed to its yield strength $f_{y k}$; the effective area of longitudinal reinforcement $A_{r}$ is stressed to its yield strength $f_{s k}$; and the effective area of concrete in compression resists a stress of $0.85 f_{c k}$, constant over the whole depth between the plastic neutral axis and the most compressed fibre of concrete. $f_{c k}$ represents the characteristic value of concrete cylinder compressive strength. The plastic stress distribution is represented in Fig. 3.

The characteristic plastic resistance moment at room temperature, $\mathrm{M}_{\mathrm{pl}, \mathrm{Rk}}$, may be determined according to Eq. (1).
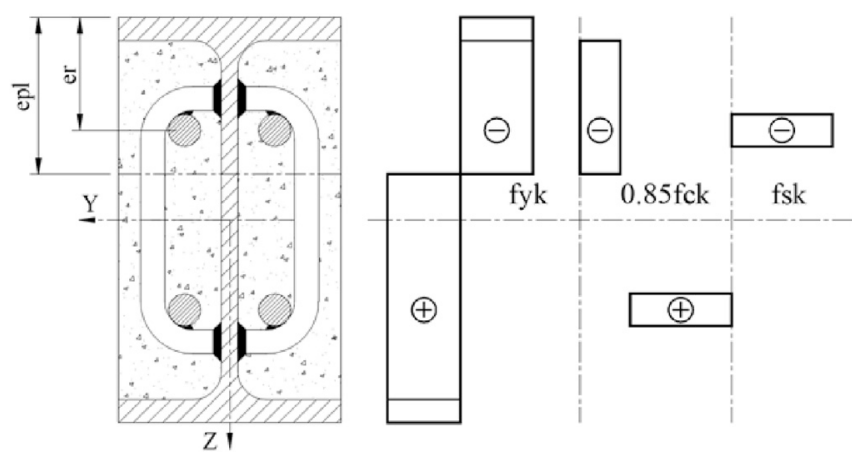

Fig. 3. Plastic stress distribution in the cross section. 


$$
\begin{gathered}
M_{p l, R k}=W_{p l, v} \cdot f_{y k}-2 \cdot f_{y k} \cdot t_{w} \cdot\left(h_{1} / 2-e_{p l}\right)^{2} / 2+ \\
2 \cdot 0.85 \cdot f_{c k} \cdot b_{1} \cdot e_{p l} \cdot\left(h_{1} / 2-e_{p l} / 2\right)+ \\
2 \cdot A_{r} \cdot\left(f_{s k}-0.85 f_{c k}\right) \cdot\left(h-2 \cdot e_{r}\right)
\end{gathered}
$$

The characteristic plastic moment resistance, $M_{p l, \theta, R k}$, at elevated temperature may be calculated, adapting the characteristic mechanical properties of each material, as shown in Eq. (2).

$$
\begin{aligned}
M_{p l, \theta, R k}= & W_{p l, y} \cdot f_{y k} \cdot k_{y \theta}-2 \cdot f_{y k} \cdot k_{y \theta} \cdot t_{w} \cdot\left(h_{1} / 2-e_{p l, \theta}\right)^{2} / 2+ \\
2 & \cdot 0.85 \cdot f_{c k} \cdot k_{c \theta} \cdot b_{1} \cdot e_{p l, \theta} \cdot\left(h_{1} / 2-e_{p l, \theta} / 2\right)+ \\
& 2 \cdot A_{r} \cdot\left(f_{s k} \cdot k_{s \theta}-0.85 \cdot f_{c k} \cdot k_{c \theta}\right) \cdot\left(h-2 \cdot e_{r}\right)
\end{aligned}
$$

The shear resistance was also analysed at room temperature. The contribution of web encasement to shear may be taken into account if stirrups are fully welded to the web, as is the case for almost specimens. The influence to the total shear resistance from steel and reinforced concrete may be assumed to be in the same proportion as it is for bending resistance [15]. At room temperature, the steel profile contribution to the bending resistance of PEB represents about $80 \%$, while the contribution of reinforced concrete is about $20 \%$.

The characteristic buckling resistance moment of unrestrained PEB at room temperature can be determined in accordance with EN 1994-1-1 [15], Eq (3), that adapts the simple calculation method presented in EN 1993-1-1 [16], using the characteristic strength of the materials.

$M_{b, R k}=\chi_{L T, \bmod } M_{p l, R k}$

The modified buckling reduction coefficient $\chi_{L T \text {,mod }}$ depends on the non-dimensional slenderness $\bar{\lambda}_{L T}$ and on the $\Phi$ factor which depends on the imperfection factor $\alpha_{L T}$. Eqs. (4)-(8).

$\chi_{L T, \bmod }=\min \left\{1 ; 1 / \lambda_{L T}^{2} ; \chi_{L T} / f\right\}$

$\chi_{L T}=1 /\left(\Phi_{L T}+\sqrt{\Phi_{L T}^{2}-\beta \bar{\lambda}_{L T}^{2}}\right) \quad ; \chi_{L T} \leq 1 \wedge \chi_{L T} \leq 1 / \bar{\lambda}_{L T}^{2}$

$\Phi_{L T}=0.5\left(1+\alpha_{L T}\left(\bar{\lambda}_{L T}-\bar{\lambda}_{L T, 0}\right)+\beta \bar{\lambda}_{L T}^{2}\right)$

$\bar{\lambda}_{L T}=\sqrt{M_{p l, R k} / M_{c r}}$

$f=1-0.5 \times\left(1-k_{c}\right) \times\left(1-2 \times\left(\bar{\lambda}_{L T}-0.8\right)^{2}\right)$

The recommended values proposed by EN1993-1-1 [16] are: the maximum value for the plateau length $\bar{\lambda}_{L T, 0}=0.4$ and the minimum value for the correction factor $\beta=0.75$. Curve "c" is proposed for lateral torsional buckling of partially encased beams, based on the buckling curves of columns in EN1994-1-1 [15], which corresponds to an imperfection factor $\alpha_{L T}=0.49$.

The elastic critical moment $M_{c r}$ is determined according to Eq. (9), based on gross cross sectional properties and takes into account the loading conditions, the real moment distribution and the restraints at supports and loading points (lateral displacement and axial rotation). This expression was calculated using the Ritz method, assuming the stationarity of the total potential energy [17], using the restraints of the experimental setup (four-point bending test with lateral displacement and axial rotation restraint at the supports and axial rotation restraint at the loading points).

$M_{c r}=30 L_{s}^{2} /\left(L_{s}-2 a\right) \sqrt{2 E I_{z} / L_{s}^{3}\left(G I_{t} / 105\left(L_{s}-2 a\right)+2 E I_{w} /\left(5\left(L_{s}-2 a\right)^{3}\right)\right)}$

$L_{s}$ represents the length between supports and $L_{l}=L_{s}-2 a$ the length between loading points, see Fig. 2. The lateral torsional buckling resistance moment of PEB is determined by the homogenized steel section, so that $E$ and $G$ in Eq. (9) represents elastic modulus and the shear modulus of steel. The second order moment of area with respect to the weak axis is represented by $I_{z}$, the torsion constant by $I_{t}$ and the warping constant by $I_{w}$, relatively to the homogenised steel section [6]. It is assumed that only the $10 \%$ of the value corresponding to the total area of concrete, with their full depth as a whole, is considered in the torsion constant of the homogenized section [15] and no concrete is considered to the warping constant of the homogenised section, see Eqs. (10) and (11).

$I_{z}=I_{z s}+E c / E s \times I_{z c}$

$I_{t}=I_{t s}+10 \% G_{c} / G_{s} I_{t c}$

Eurocode EN1994-1-2 [13] does not consider lateral torsional buckling as a potential failure mode to PEB without concrete slab under fire. To determine the characteristic buckling resistance moment at time $t$, $M_{b . f, t, R k}$, the simplified formulae of Eurocode EN1993-1-2 [14] may be adapted for composite sections, using Eq. (12).

$M_{b, f i, t, R k}=\chi_{L T, f i} M_{p l, \theta, R k}$

The buckling reduction coefficient at elevated temperatures $\chi_{L T, f i}$ depends on the non-dimensional slenderness $\bar{\lambda}_{L T, \theta, c o m}$ and on the $\Phi_{L T, \theta, c o m}$ factor, which depends on the imperfection factor $\alpha$ under fire conditions. Eqs. (13) and (14).

$\chi_{L T, f i}=1 /\left(\Phi_{L T, \theta, c o m}+\sqrt{\left(\Phi_{L T, \theta, c o m}\right)^{2}-\left(\bar{\lambda}_{L T, \theta, c o m}\right)^{2}}\right)$

$\Phi_{L T, \theta, \mathrm{com}}=0.5\left(1+\alpha \bar{\lambda}_{L T, \theta, \mathrm{com}}+\left(\bar{\lambda}_{L T, \theta, \mathrm{com}}\right)^{2}\right)$

The non-dimensional slenderness at elevated temperature $\bar{\lambda}_{L T, \theta, c o m}$ depends on the ratio between the characteristic plastic moment resistance of PEB section and the elastic critical moment, both calculated at elevated temperature (temperature assumed constant between the supports).

$\bar{\lambda}_{L T, \theta, c o m}=\sqrt{M_{p l, \theta, R k} / M_{c r, \theta}}$

The elastic critical moment depends on the load and support conditions, being the geometric properties of PEB section approximated by Eqs. (16) and (17), according to the characteristics of the homogenised section, affecting the material properties by their reduction factors, $E_{a, \theta}=$ $K_{E, \theta} E_{a}$ and $G_{a, \theta}=K_{E, \theta} G_{a}$ for structural steel, $E_{c, \theta}=K_{E, \theta} E_{c}$ and $G_{c, \theta}=$ $K_{E, \theta} G_{c}$ for concrete, and $E_{s, \theta}=K_{E, \theta} E_{s}$ for reinforced steel. The warping constant of the homogenised steel section, $I_{w}$, is approached by the warping constant of the steel section, $I_{w a}$, as specified for room temperature analysis.

$I_{z}=I_{z a}+E_{c, \theta} / E_{a, \theta} \cdot\left(b-t_{w}\right)^{3} \times\left(h-2 t_{f}\right) / 12+\left(E_{s, \theta}-E_{c, \theta}\right) / E_{a, \theta} A_{s} y_{r}^{2}$

$I_{t}=I_{t, a}+0,1 \cdot G_{c, \theta} / G_{a, \theta} \times 1 / 3\left(1-0.63\left(b / h-2 t_{f}\right)\right)\left(h-2 t_{f}\right) b^{3}$

The imperfection factor $\alpha$ depends on the steel grade $f_{y}$ of the material being used, EN1993-1-2 [14], Eq. (18).

$\alpha=0.65 \sqrt{235 / f_{y}}$

Vila Real et al. [18] proposed a new formulae to be used in fire conditions, using the same approach for lateral torsional buckling design, taking into account the moment distribution between the lateral restraints. The reduction factor should be modified to $\chi_{L T, f, \text { mod }}$, according to Eq. (19). 
$\chi_{L T, f i \text {, mod }}=\chi_{L T, f i} / f \quad ; \chi_{L T, f i, \bmod } \leq 1$

The factor $f$ depends on the load type, using a correction factor $k_{c}$, according to Eq. (20). This approach makes factor $f$ equal to 1.0, because $k_{c}$ also equals 1.0, when considering four-point bending configuration, being $\chi_{L T, f i \text { mod }}=\chi_{L T, f i}$ in this case.

$f=1-0.5\left(1-k_{c}\right)$

\section{Bending resistance - experimental tests}

Twenty seven specimens were tested, divided into ten series. Two or three tests were considered for repeatability in each series and the results agree very well. Specimens were tested using a steel reaction portal frame, with two fork supports, see Fig. 2.

Tests developed at elevated temperature, used electro-ceramic resistances to increase and maintain elevated temperature during loading. The control unit read, in real time, the temperature of two and four control points (on the top and bottom of the flanges), for medium and large test series respectively. Five different cross sections were defined to measure temperature (S1, S1A, S2, S3A and S3), and one cross section (SM) was defined to measure axial strain and displacements (vertical $Z_{G}$, lateral $Y_{G}$ ).

Four-point bending test configuration was used to evaluate the bending performance of laterally unrestrained PEB at elevated and room temperature, see Table 1 . The bending resistance was also compared to bare steel beams.

Two series (3-8) were prepared to analyse the behaviour of stirrups not welded to the web, four series $(1,2,6,7)$ were prepared for testing the behaviour of PEB at elevated temperature using welded stirrups and four series $(4,5,9,10)$ were prepared to be tested at room temperature. Two slenderness ratio were considered, using beams with total length Lt equal to $2.5 \mathrm{~m}$ and $4.0 \mathrm{~m}$.

Some important load events were recorded for each test. The proportional limit force $F_{p}$, the force $F_{y}$ that results from the intersection method between two straight lines drawn from linear and non-linear interaction of the vertical displacement; the load event for the displacement limit $\mathrm{F}_{\mathrm{L} / 30}$; and the maximum load level for the asymptotic behaviour of lateral displacement $\mathrm{P}_{\mathrm{u}}$.

\subsection{Specimens and materials}

PEB were casted in the laboratory, without the need of formwork. Specimens were tested after more than 60 days, with respect to the first casting phase, to ensure normal bond adhesion. The second casting phase was performed one week after the first. This time delay did not influence the behaviour of PEB, because the second casting used the same concrete composition and the same environmental conditions. Both casting phases had sufficient cure time and concrete presented the same resistance in both stages.

The surface of materials had no special treatment and were used as delivered by manufacturers. Steel elements were cut from long steel beams, using traditional machinery and stirrups were welded to the web of steel profile using a MIG/MAG welding system. Reinforcement was spot welded to stirrups in the case of PEB with welded stirrups and tied with wire rope in the case of PEB without welded stirrups.

The geometric imperfection was also characterized by the laser method, measuring the distance between a perfect line (laser beam) and the lateral imperfection of geometry, spaced every $0.5 \mathrm{~m}$, see Table 1 for the maximum lateral imperfection. The characteristic geometry of every IPE100 was also measured and the average dimensions of the main components were determined (mm) and took into account: $\overline{\mathrm{t}}_{\mathrm{w}}=4.5, \overline{\mathrm{t}}_{\mathrm{f}}=$ $5.8, \overline{\mathrm{h}}=102.4$ and $\overline{\mathrm{b}}=54.8$.

The steel was characterized according to international standards [19] for hot rolled and cold formed, see Table 2 . Three samples were collected from the web of the hot rolled steel profile and two more samples were collected from steel reinforcement. The elastic modulus $E$, the proof strength for $0.2 \%$ strain $R_{\text {p. } 0.2 \%}$, the upper yield strength $R_{e H}$, the lower yield strength $R_{e L}$, the tensile strength $R_{m}$ and the total extension at the moment of fracture At are presented in this table.

Concrete was made with Portland cement, sand and siliceous aggregates. The compressive strength of concrete was determined according to

Table 1

List of tested beams (specimens) and main force events.

\begin{tabular}{|c|c|c|c|c|c|c|c|c|c|c|}
\hline Series & Specimen & $\begin{array}{l}\text { Length } \\
\text { Ls [m] }\end{array}$ & $\begin{array}{l}\text { Stirrups } \\
\text { [W/NW] }\end{array}$ & $\begin{array}{l}\text { Temp. } \\
{\left[{ }^{\circ} \mathrm{C}\right]}\end{array}$ & $\begin{array}{l}\text { Max. } \\
\text { Imp. Abs. } \\
{[\mathrm{mm}]}\end{array}$ & $\begin{array}{l}\mathrm{F}_{\mathrm{Mpl}} \\
{[\mathrm{N}]} \\
\text { (Eq. (1)) (Eq. (2)) }\end{array}$ & $\begin{array}{l}\mathrm{F}_{\mathrm{p}} \\
{[\mathrm{N}]}\end{array}$ & $\begin{array}{l}\mathrm{F}_{\mathrm{y}} \\
{[\mathrm{N}]}\end{array}$ & $\begin{array}{l}\mathrm{F}_{\mathrm{L} / 30} \\
{[\mathrm{~N}]}\end{array}$ & $\begin{array}{l}\mathrm{P}_{\mathrm{u}} \\
{[\mathrm{N}]}\end{array}$ \\
\hline \multirow[t]{3}{*}{1} & B/2.4-01 & & & & 2 & & 11910 & 18890 & 24932 & 38864 \\
\hline & $\mathrm{B} / 2.4-02$ & 2.4 & $\mathrm{~W}$ & 400 & 2 & 32013 & 13627 & 21760 & 26583 & 31533 \\
\hline & $\mathrm{B} / 2.4-03$ & & & & 2 & & 12540 & 19920 & 24878 & 33568 \\
\hline \multirow[t]{3}{*}{2} & B/2.4-04 & & & & 1 & & 24770 & 31430 & 34060 & 36875 \\
\hline & $\mathrm{B} / 2.4-05$ & 2.4 & $\mathrm{~W}$ & 200 & 2 & 32388 & 26030 & 30350 & 32953 & 39042 \\
\hline & B/2.4-06 & & & & 1 & & 26580 & 31380 & 33930 & 34712 \\
\hline \multirow[t]{3}{*}{3} & $\mathrm{~B} / 2.4-07$ & & & & 1 & & 13050 & 20610 & 24898 & 29000 \\
\hline & $\mathrm{B} / 2.4-08$ & 2.4 & NW & 400 & 1 & 32013 & 12960 & 19270 & 25135 & 40861 \\
\hline & $\mathrm{B} / 2.4-09$ & & & & 1 & & 11920 & 20850 & 25722 & 33246 \\
\hline \multirow[t]{3}{*}{4} & $\mathrm{~B} / 2.4-10$ & & & & 2 & & 27050 & 34966 & 35000 & 35015 \\
\hline & $\mathrm{B} / 2.4-11$ & 2.4 & W & room & 0.5 & 32584 & 25960 & 35410 & 36360 & 37624 \\
\hline & $\mathrm{B} / 2.4-12$ & & & & 3 & & 26600 & 34600 & 35962 & 39246 \\
\hline \multirow[t]{2}{*}{5} & $\mathrm{~B} / 2.4-11 \mathrm{~A}$ & 2.4 & - & room & 1 & 26273 & 16107 & - & - & 29627 \\
\hline & $\mathrm{B} / 2.4-12 \mathrm{~A}$ & & & & 2 & & 15530 & - & - & 28477 \\
\hline \multirow[t]{3}{*}{6} & B/3.9-01 & & & & 2 & & 11190 & 16370 & 22126 & 30204 \\
\hline & B/3.9-02 & 3.9 & $\mathrm{~W}$ & 400 & 5 & 32013 & 11920 & 16360 & 22715 & 27290 \\
\hline & B/3.9-03 & & & & 3 & & 11700 & 14850 & 22573 & 28337 \\
\hline \multirow[t]{3}{*}{7} & B/3.9-04 & & & & 2 & & 4110 & 9620 & 12641 & 22456 \\
\hline & B/3.9-05 & 3.9 & W & 600 & 2 & 14949 & 4360 & 9750 & 12996 & 21662 \\
\hline & B/3.9-06 & & & & 5 & & 4090 & 9110 & 12025 & 22770 \\
\hline \multirow[t]{3}{*}{8} & B/3.9-07 & & & & 5 & & 11170 & 15260 & 22665 & 23591 \\
\hline & B/3.9-08 & 3.9 & NW & 400 & 5 & 32013 & 13160 & 16540 & 24237 & 32642 \\
\hline & B/3.9-09 & & & & 2 & & 10720 & 15400 & 23200 & 24815 \\
\hline \multirow[t]{2}{*}{9} & B/3.9-11 & 3.9 & $\mathrm{~W}$ & room & 2 & 32584 & 26500 & 31350 & 35405 & 38718 \\
\hline & B/3.9-12 & & & & 5 & & 29020 & 32010 & 36159 & 36264 \\
\hline \multirow[t]{2}{*}{10} & $\mathrm{~B} / 3.9-11 \mathrm{~A}$ & 3.9 & - & room & 1 & 26273 & 15023 & - & - & 19436 \\
\hline & $\mathrm{B} / 3.9-12 \mathrm{~A}$ & & & & 3 & & 15331 & - & - & 21272 \\
\hline
\end{tabular}


Table 2

Tensile tests for hot rolled and cold formed steel.

\begin{tabular}{|c|c|c|}
\hline \multirow[t]{2}{*}{ Properties } & Steel profile & Steel reinforcement \\
\hline & Average \pm S. D. & Average \pm S. D. \\
\hline $\mathrm{E}[\mathrm{GPa}]$ & $197.9 \pm 2.9$ & $203.3 \pm 2.1$ \\
\hline $\mathrm{R}_{\mathrm{p} .0 .2 \%}[\mathrm{MPa}]$ & $300.7 \pm 6.7$ & $525.0 \pm 3.5$ \\
\hline $\operatorname{ReH}[\mathrm{MPa}]\left(\mathrm{f}_{\mathrm{yk}}\right)\left(\mathrm{f}_{\mathrm{sk}}\right)$ & $302.4 \pm 5.7$ & $531.5 \pm 7.9$ \\
\hline ReL [MPa] & $300.8 \pm 4.0$ & $520.8 \pm 4.1$ \\
\hline $\mathrm{Rm}$ [MPa] (fu) & $431.2 \pm 5.0$ & $626.6 \pm 11.5$ \\
\hline At [\%] & $41.6 \pm 0.2$ & $25.2 \pm 0.5$ \\
\hline
\end{tabular}

Table 3

Compressive test results for concrete.

\begin{tabular}{lll}
\hline Properties & Cure [days] & Average \pm S. D. \\
\hline $\mathrm{f}_{\text {ck,cube }}[\mathrm{MPa}]$ & 29 & $21.4 \pm 1.0$ \\
$\mathrm{f}_{\text {ck }}[\mathrm{MPa}]$ & 29 & $20.4 \pm 0.3$ \\
\hline
\end{tabular}

the European standard [20], using 3 samples for cubic and cylindrical geometry and the results are presented in Table 3 . The mixture of $1\left[\mathrm{~m}^{3}\right]$ of concrete presented a mass of sand equal to 1322.7 [kg], the mass of aggregates was equal to 451.1 [kg] and the volume of water was 198 [1]. The mass of cement was 466.7 [kg], which gave a water/cement ratio of $45 \%$. The aggregates (gravel and sand) were characterized by the sieving method and tested according to the European standard [21] to determine the particle size distribution. Due to the small size of the steel section and considering the offset dimension for the concrete cover of the stirrups, the concrete used small-sized aggregates. The percentage of aggregates with diameters between 4 and $6 \mathrm{~mm}$ was $90 \%$, while the percentage of sand with diameters between 0.063 and $0.5 \mathrm{~mm}$ was $80 \%$. The aggregate dimensions limit the value of the compressive resistance of concrete, as concluded by Keru et al., [22]. The high level of permeability at elevated temperature was responsible for the pore pressure decrease, justifying the absence of explosive spalling.

PEB were prepared to be tested at room temperature, measuring strain in central section (SM), over steel flange and web, in hot rolled section (SM-FS and SM-WS) and over concrete (SM-RS1 and SM-RS2). Whereas perfect bond was assumed between concrete and reinforcement, concrete strain was measured on steel reinforcement. All five strain gauges were protected with gloss and special viscous putty against aggression of moisture, water and mechanical damage.

PEB were also prepared to be tested at elevated temperatures, using thermocouples type $\mathrm{K}$, positioned in five sections along the length of the beam. Some thermocouples were also welded to a small steel washer and wrapped in concrete for its temperature measurements, at positions Si-IC and $\mathrm{Si}-\mathrm{OC}$.

\subsection{Experimental set-up and test procedure}

Tests developed at room temperature used quasi-static load increments, based on four load cell readings. Load was applied with two synchronized hydraulic jacks. Strain, displacement and cross section rotation were determined at central section (SM).

Tests developed at elevated temperature used electro-ceramic heating unit to increase and maintain elevated temperature during the mechanical loading. A heating rate of $800{ }^{\circ} \mathrm{C} /$ hour was applied on the top and bottom flanges of the beams, which lead to heating periods of 15, 30 and 45 min to attain $200{ }^{\circ} \mathrm{C}, 400{ }^{\circ} \mathrm{C}$, and $600{ }^{\circ} \mathrm{C}$. A ceramic mat insulation was used around the beams to increase the heating efficiency. Supports were adjusted and load was applied after temperature stabilization over the cross section (60, 90 and 120 min after the start of heating). The vertical and lateral displacement and the cross section rotation were measured in the central section. Load events and temperature measurements were also recorded in the main cross sections.

Two fork supports were materialized as simple supports. Restraint
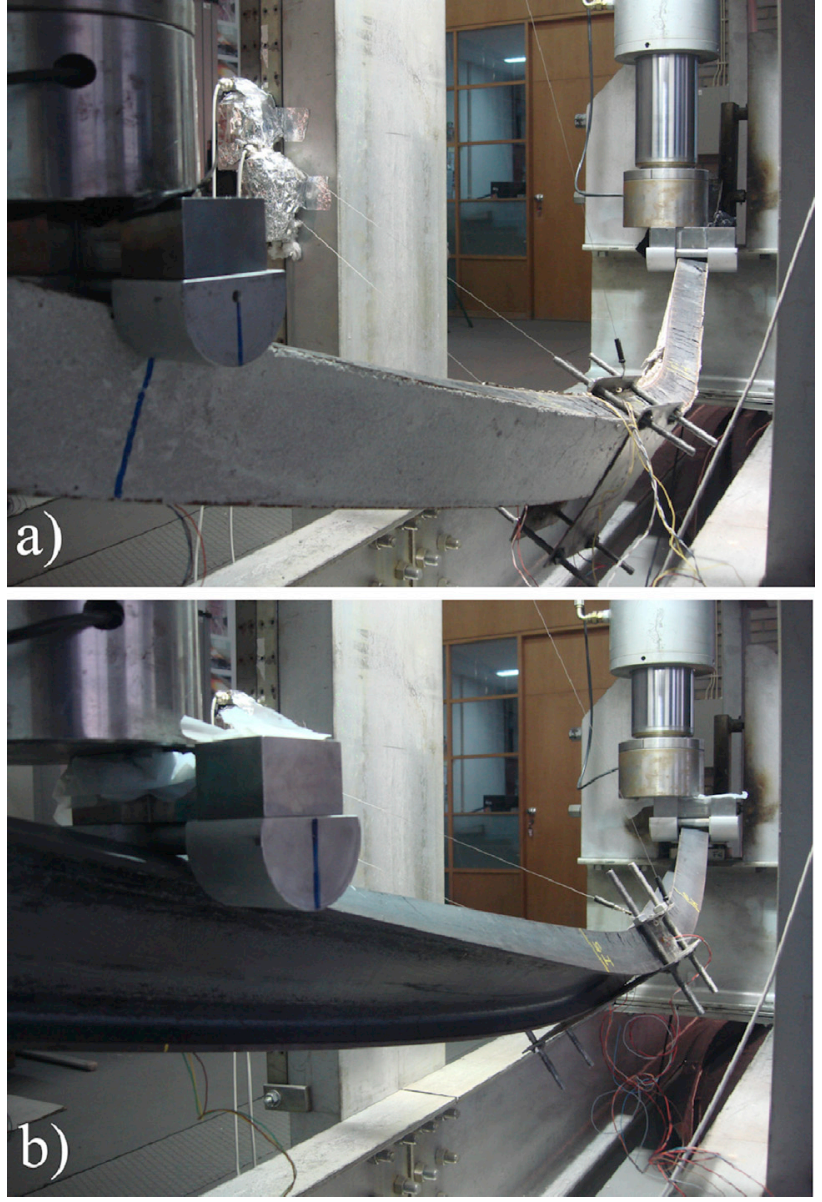

Fig. 4. Deformed mode shape for test specimen $B / 2.4-12$ a) and $B / 2.4-11 A$ b).

against $\mathrm{Y}$ and $\mathrm{Z}$ displacement and restraint against $\mathrm{X}$ rotation were applied at each support. A contact steel interface was developed to apply the vertical load, introducing a level of restraint against $X$ rotation but allowing for lateral displacement $\mathrm{Y}$, using Teflon to reduce friction between the steel interface and the hydraulic jack.

The length of specimens to be heated ( $\mathrm{Lf}=1300 \mathrm{~mm}$ for series $1-5$ and $\mathrm{Lf}=2700 \mathrm{~mm}$ for series 6-10) was shorter than the length between loading points $(\mathrm{Ll}=1500 \mathrm{~mm}$ for series $1-5$ and $\mathrm{Ll}=3000 \mathrm{~mm}$ for series $6-10)$. The distance between load and support was kept constant for all series $(450 \mathrm{~mm})$. Free thermal elongation was allowed before adjusting both supports and the start of loading in each test.

Vertical and lateral displacements $\left(Z_{G}, Y_{G}\right)$ as well as cross section rotation $\theta_{G}$ were calculated on the basis of the measurement of three wire potentiometric displacement transducer.

The two-point load and reactions were measured by load cells, being the load averaged to draw force displacement results.

\subsection{Results at room temperature}

The bending performance of PEB was compared with the performance of bare steel beam at room temperature (series 4-5 and series 9-10), using the same steel profile. This comparison can be used to understand the lateral torsional buckling behaviour at elevated temperatures. The load deflection behaviour is different in particular during post buckling (see vertical displacement after achieving the proportional limit force), although both attained the lateral torsional buckling as deformed mode shape. The flexural stiffness of PEB is $15 \%$ higher than bare steel beam (for both length series). Fig. 4 shows the deformed mode shape for the last load step of each beam (PEB and bare steel).

Figs. 5-6 present the vertical or transversal displacement history for 


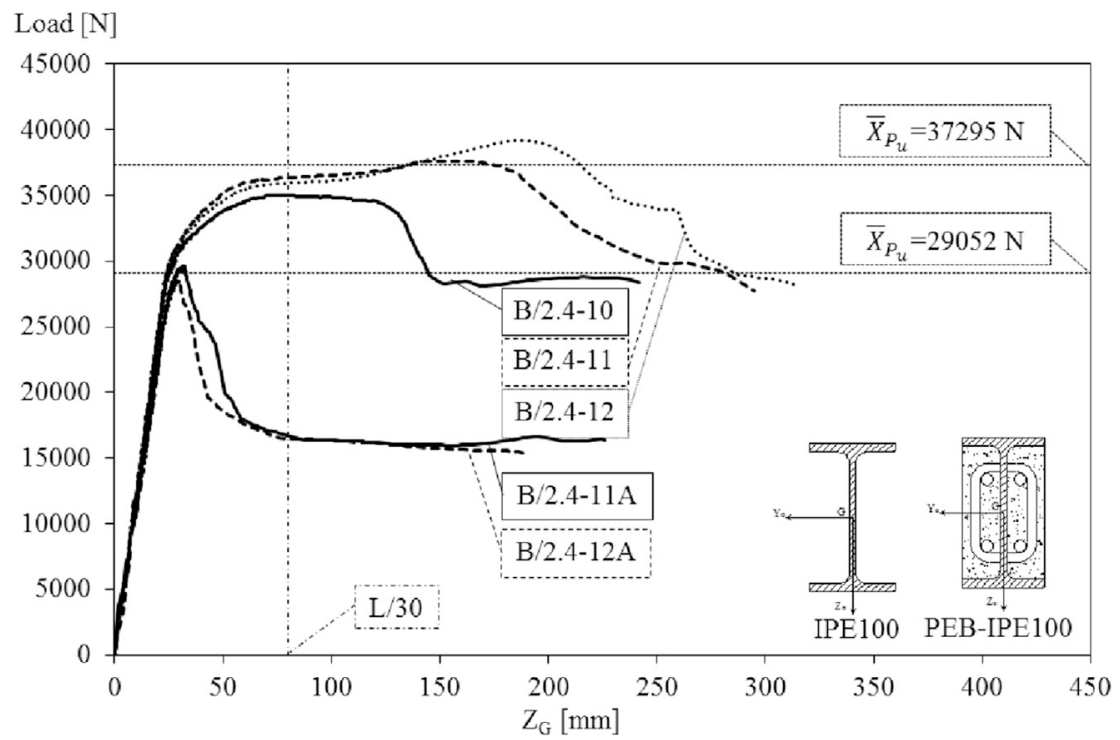

Fig. 5. Vertical displacement for medium series 4-5.

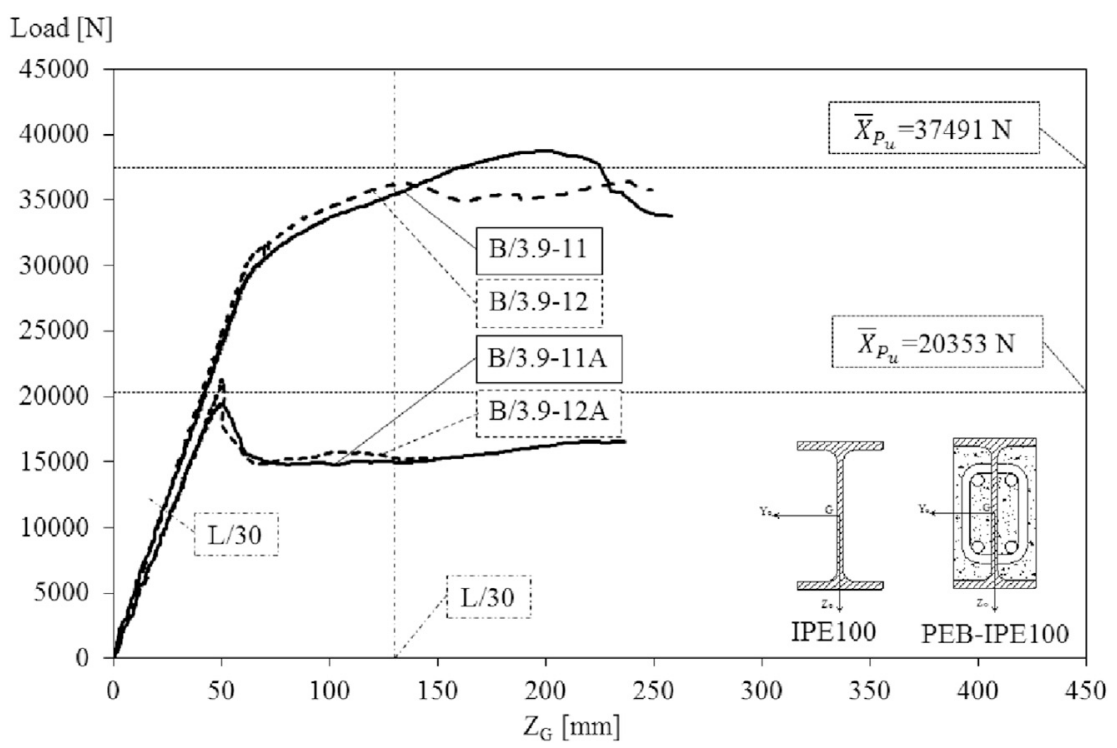

Fig. 6. Vertical displacement for large series 9-10.

each length series. The encased reinforced concrete between the flanges causes, in specimens exposed to room temperature, an increase in ultimate load $\mathrm{P}_{\mathrm{u}}$ of $28.4 \%$ and $84.2 \%$ for PEB series 4 and 9 with respect to IPE bare steel series 5 and 10, respectively.

The main load events are also compared between PEB and bare steel beam. Due to different load deflection behaviour, only the ultimate load, $P_{u}$, is able to be compared, see Table 4 . This load event $\bar{X}_{P_{u}}$ corresponds to the average of the maximum load of each series. Both length series

Table 4

Main load events to bending resistance on PEB series 4-5 and 9-10.

\begin{tabular}{lllll}
\hline Series & $\bar{X}_{P_{u}}[\mathrm{~N}]$ & $\bar{X}_{F_{L / 30}}[\mathrm{~N}]$ & $\bar{X}_{F_{y}}[\mathrm{~N}]$ & $\bar{X}_{F_{p}}[\mathrm{~N}]$ \\
\hline 4 & 37295 & 36161 & 35008 & 26537 \\
5 & 29052 & - & - & - \\
9 & 37491 & 35782 & 31680 & 27760 \\
10 & 20354 & - & - & - \\
\hline
\end{tabular}

confirmed that post buckling is quite different between PEB and bare steel I beams. After the bifurcation point, load decreased in bare steel beams, as expected.

Lateral displacement exhibits similar behaviour in both PEB and bare steel beams, see Figs. 7-8. The increase in lateral displacement is followed by a decrease of load, after reaching the bifurcation point. The positive or negative value of displacement depends mainly on the geometric imperfection of each beam. At the end of some tests, during the post buckling stage, the increase of load may be justified by the restraining forces of the supports, due to the high level of displacement (vertical and lateral).

PEB and bare steel beams behaved on the elastic and plastic region for the case of medium series $4-5$, as verified by the strain records, see Figs. 9-10. The average value for the load limit of proportionality, $\bar{X}_{F_{p}}$, is also represented in the graph for comparison with strain measurements, being this load event coincident with the yielding limit of the flanges. The elastic limit for strain over steel is also depicted on both graphs. The strain is initially linear proportional to load, changing its behaviour after 


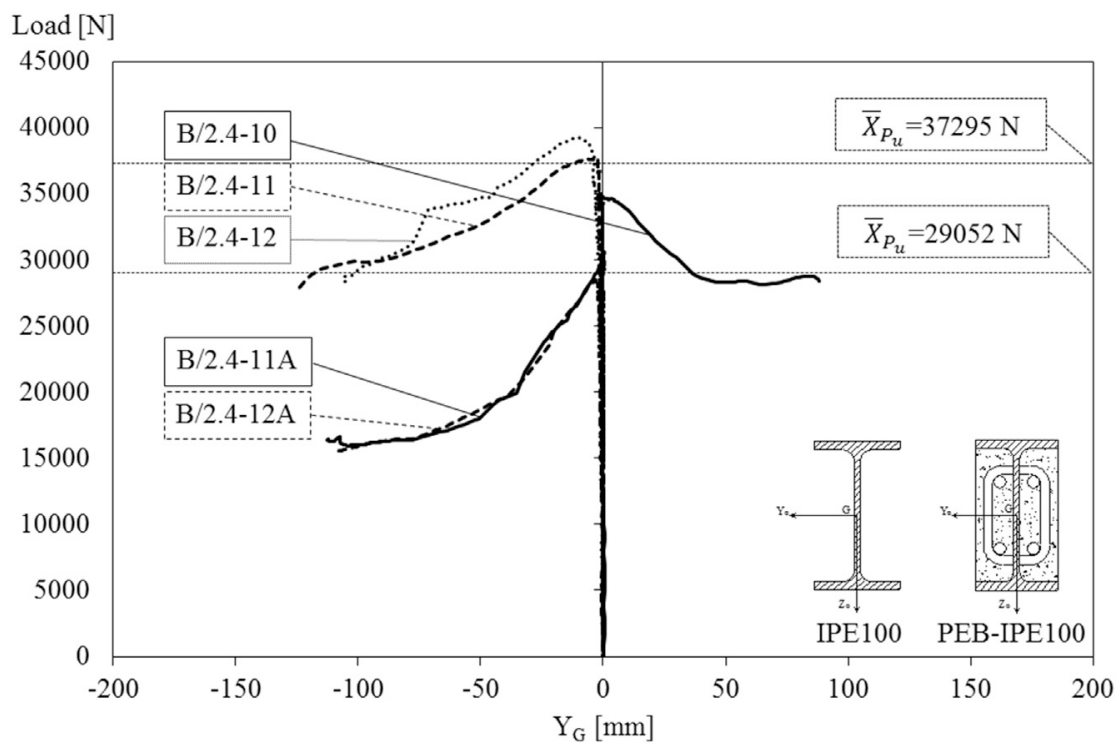

Fig. 7. Lateral displacement of test series 4-5.

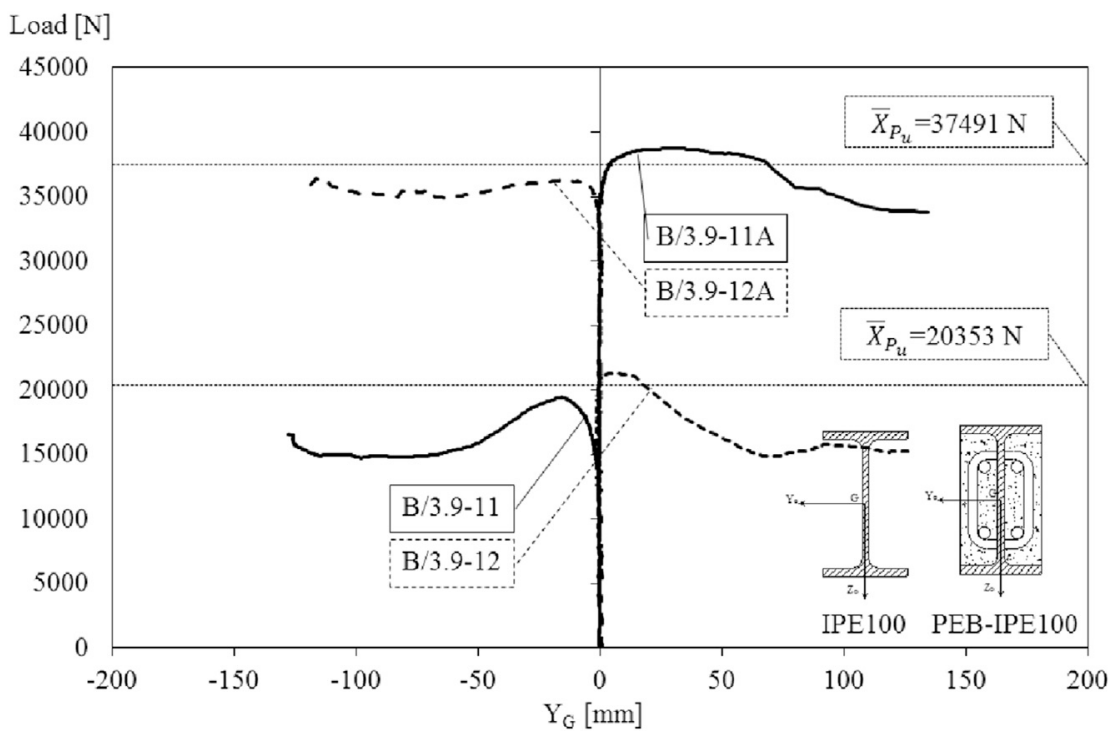

Fig. 8. Lateral displacement of test series 9-10.

reaching the yielding limit of the material.

The large PEB series (9) behaved in elastic and plastic region, while bare steel beam, series 10, with same length did not reach the yielding limit see Figs. 11 and 12. The decrease of the load in bare steel beam, after bifurcation point, also produced a decrease in strain, following the same curve used before reaching that point.

\subsection{Results at elevated temperature}

The bending performance of PEB was compared for different temperature levels $\left(200{ }^{\circ} \mathrm{C}, 400{ }^{\circ} \mathrm{C}\right.$, and $600{ }^{\circ} \mathrm{C}$ ), corresponding to bending tests (1-2) of medium series and to the bending test of large series (6-7). The deformed failure modes of PEB are represented in Figs. 13-15, as an example of each test series. Lateral torsional buckling mode was verified for all tested beam series between 200 and $400{ }^{\circ} \mathrm{C}$ and for all beam length. For the higher testing temperature $\left(600{ }^{\circ} \mathrm{C}\right)$, and for the large specimen series, all tested beams revealed the formation of a plastic hinge without any significant lateral displacement. Due to high magnitude of vertical displacement and also due to effect of plasticity, the deformed failure mode for all tests of series 7 (PEB at $600{ }^{\circ} \mathrm{C}$ ) is dominated by plastic hinge formation (PH), rather than by LTB. No significant lateral displacement was determined, see Fig. 28. This emphasises the main difference behaviour in LTB between PEB and bare steel beams. The same bare steel beam was already submitted to $600{ }^{\circ} \mathrm{C}$ and attained LTB as deformed failure mode [23]. More tests should be developed at this temperature level using different PEB lengths.

Temperature was recorded in several cross sections along each beam length. Figs. 16-18 provide an example of the heating performance of PEB tested at $200{ }^{\circ} \mathrm{C}, 400{ }^{\circ} \mathrm{C}$, and $600{ }^{\circ} \mathrm{C}$, respectively for test of specimen $\mathrm{B} / 2.4-04, \mathrm{~B} / 3.9-01$ and $\mathrm{B} / 3.9-05$. The increase of temperature follows the heating rate of $800{ }^{\circ} \mathrm{C} / \mathrm{h}$, revealing the moisture effect near $100{ }^{\circ} \mathrm{C}$. The average temperature on the cross section (S2) converges to the specified temperature of each test. Due to high temperature of the test series $7\left(600{ }^{\circ} \mathrm{C}\right)$, a higher difference between maximum and minimum 


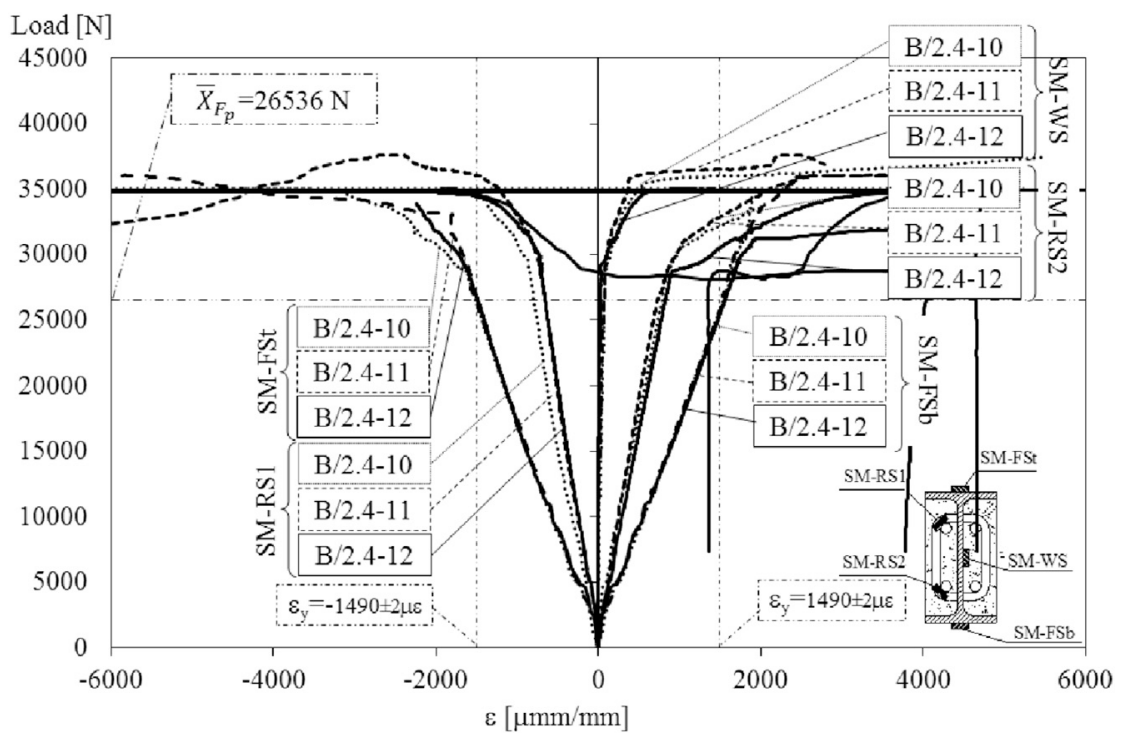

Fig. 9. Strain records, for series 4 .

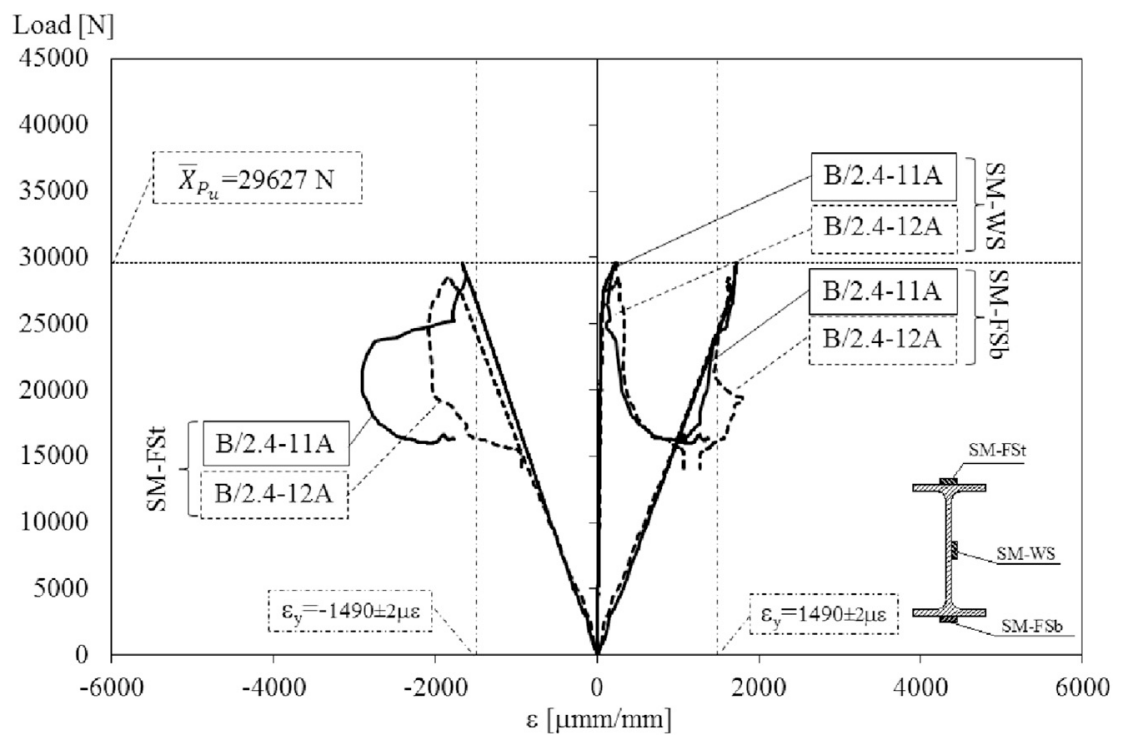

Fig. 10. Strain records, for series 5 .

temperature was detected in this cross section, mainly justified by insufficient insulation.

Both stages of experiment are identified, corresponding to the increase of the temperature of the beam (stage 1) and later by the increase of the mechanical load (stage 2. Temperature evolution were also obtained in the other sections (S1, S1A, S3, S3A) [24].

Figs. 19-21 show the infrared thermography of three specimens immediately after removing the insulation, representative of each temperature test $\left(200{ }^{\circ} \mathrm{C}, 400{ }^{\circ} \mathrm{C}\right.$, and $\left.600{ }^{\circ} \mathrm{C}\right)$. The temperature gradient along $\mathrm{X}$ axis is verified near the extremities of heated length (section $\mathrm{S} 3 \mathrm{~A}$ ), proving the existence of the heat flow along the beam axis. Similar gradient was verified in section S1A. The heat flow was also verified from the inside of the beam to the outside. The maximum temperature on the external surface of the insulation blanket was 80,200 and $270{ }^{\circ} \mathrm{C}$, for specimens $\mathrm{B} / 2.4-04, \mathrm{~B} / 3.9-01$ and $\mathrm{B} / 3.9-05$, during tests.

The temperature profile along the beam length was also calculated by the average values of the temperatures measured in each cross section $\mathrm{S} 1$, S1A, S2, S3A, and the thermocouples of the heating device. The average temperature in section $\mathrm{S} 3 \mathrm{~A}$ is smaller than temperature of the test, due to boundary condition effect (heat flow along the beam to the extremities, confirmed by results of infrared thermography). For each test, only three time instants are depicted on Figs. 22-24. Two intermediate time instants were considered during the heating phase and the last is close to the start of the incremental load ( $\mathrm{t} 1$ ). All other tested revealed similar performance, being the results of series 2-6-7 representative of the tests developed at $200{ }^{\circ} \mathrm{C}, 400{ }^{\circ} \mathrm{C}$, and $600{ }^{\circ} \mathrm{C}$. Test results of series 7 show an important temperature gradient near the extremities of the heating length of approximately $0.455{ }^{\circ} \mathrm{C} / \mathrm{mm}$, being higher than temperature gradient of series 2 and $6\left(0.286^{\circ} \mathrm{C} / \mathrm{mm}\right.$ and $0.306^{\circ} \mathrm{C} / \mathrm{mm}$, respectively). This temperature gradient is of some importance when doing the comparison of the results, because it represents an extra amount of resistance that is not consider in the simple calculation method. The simple calculation method assumes constant temperature over the length Lf.

Fig. 25 represents the results of vertical displacement for medium series 1-2-4, used to analyse the temperature effect on bending resistance for the case of beams with welded stirrups. The measured load versus 


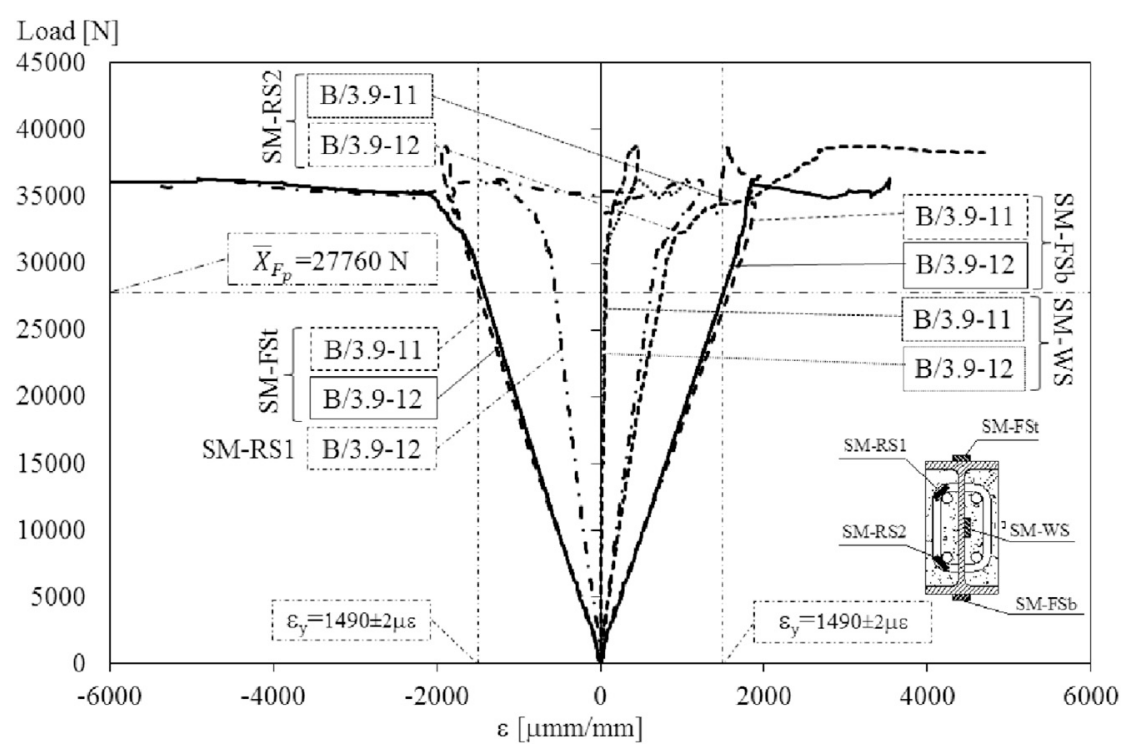

Fig. 11. Strain records, for series 9.

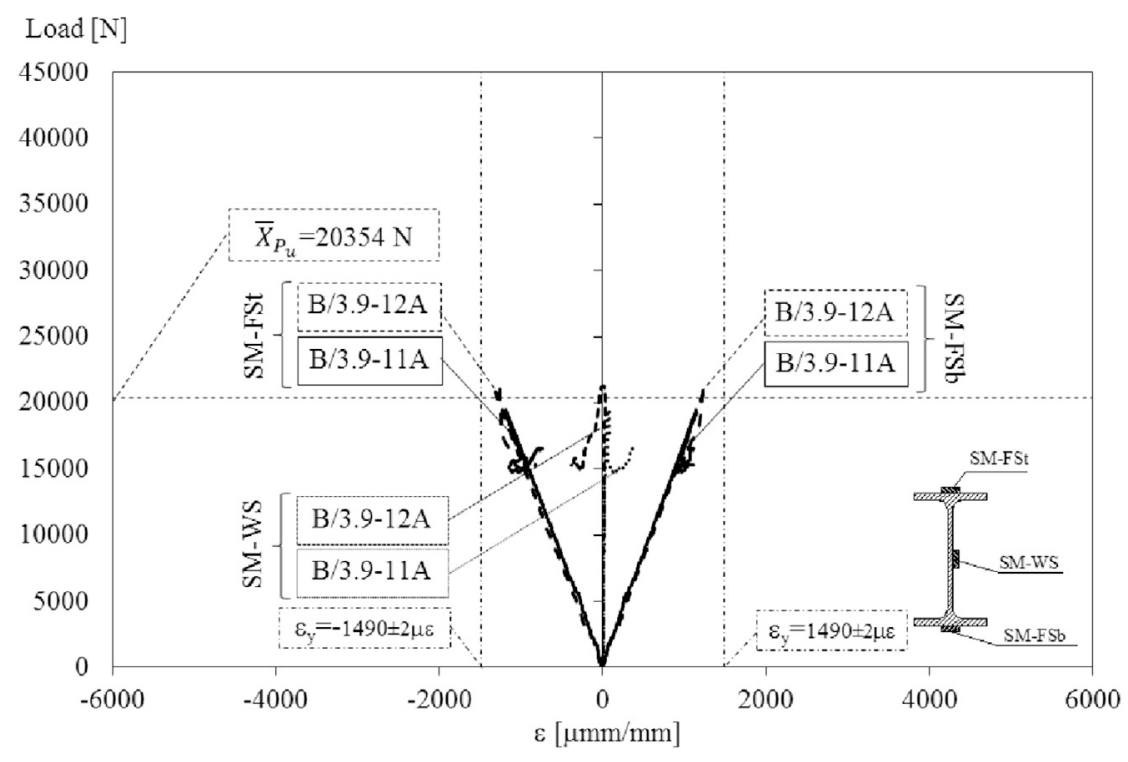

Fig. 12. Strain records, for series 10 .

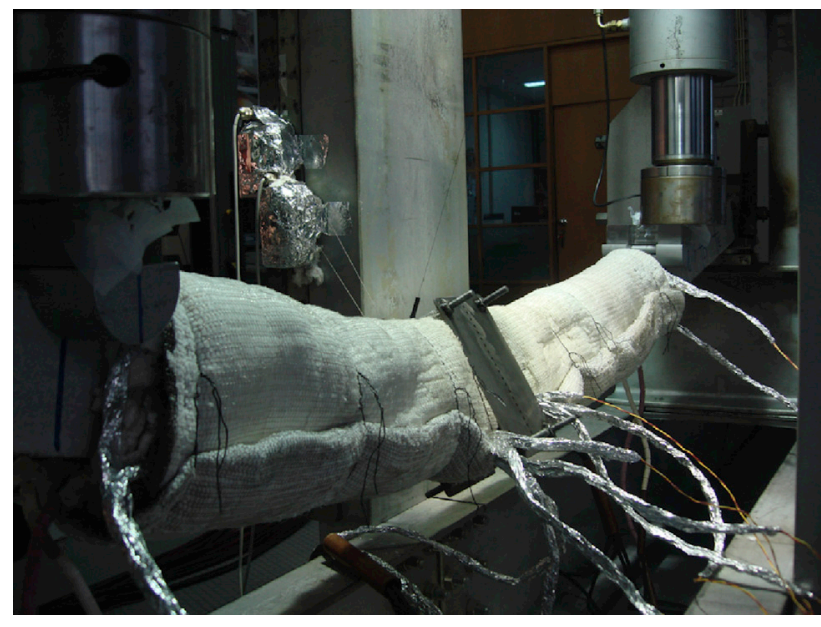

Fig. 13. Deformed failure mode for test specimen $\mathrm{B} / 2.4-04$, tested at $200{ }^{\circ} \mathrm{C}$.

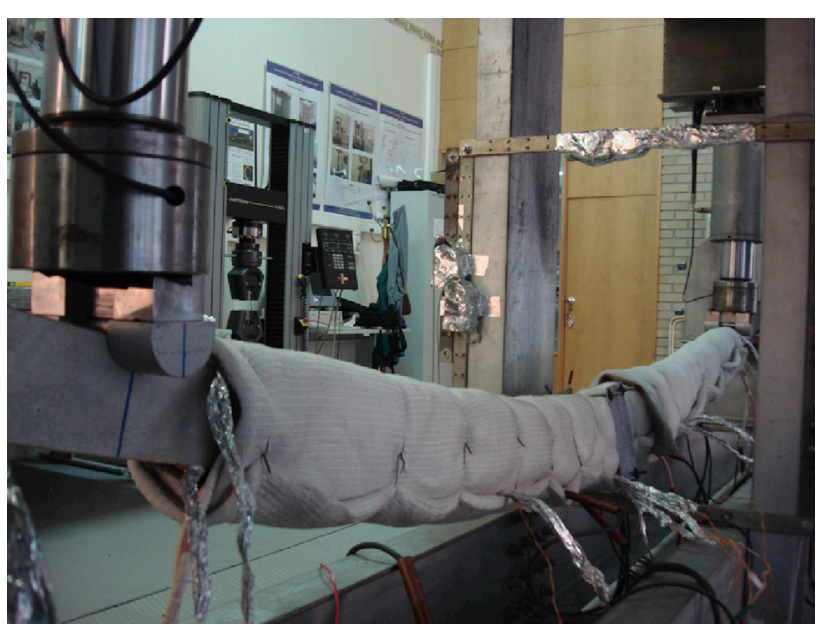

Fig. 14. Deformed failure mode for test specimen B/3.9-01, tested at $400{ }^{\circ} \mathrm{C}$. 


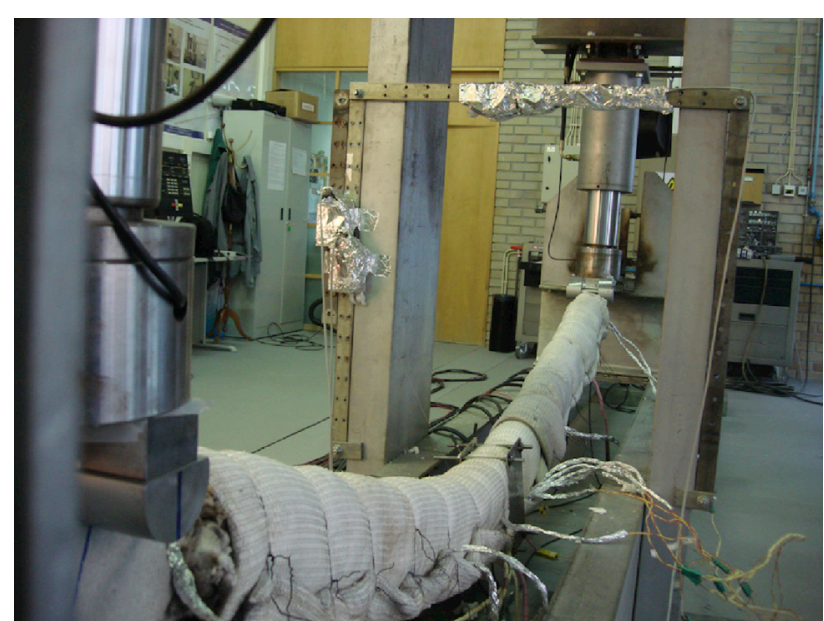

Fig. 15. Deformed failure mode for test specimen B/3.9-05, tested at $600{ }^{\circ} \mathrm{C}$.

vertical displacement is represented, sowing similar behaviour for different temperature level. Results agree very well for the specimens of the same series, with exception to the ultimate loads $F_{u}$ (very large displacements). All tested beams reached lateral torsional buckling (LTB) as deformed failure mode.

Fig. 26 shows the results of the vertical displacement for large series 6-7-9, also used to analyse the temperature effect on the bending resistance of the large PEB series.

Table 5 presents the main load events for the medium and large series, with welded stirrups. PEB exposed to $200{ }^{\circ} \mathrm{C}$ present a reduction of $1.1 \%$ in $\mathrm{F}_{\mathrm{u}}$ relative to $\mathrm{PEB}$ at room temperature, $7 \%$ in the load event for the displacement limit $\mathrm{F}_{\mathrm{L} / 30}, 11.3 \%$ in the load event $\mathrm{F}_{\mathrm{y}}$ and $2.8 \%$ in the load limit $\mathrm{F}_{\mathrm{p}}$. Although $\mathrm{PEB}$ subjected to $400{ }^{\circ} \mathrm{C}$ just present a $7 \%$ reduction in the value of the ultimate load $\mathrm{P}_{\mathrm{u}}$ with respect to room temperature, there is a big difference in the other load events: the load for the displacement limit $\mathrm{F}_{\mathrm{L} / 30}$ was reduced by $29.5 \%$, the yield force $\mathrm{F}_{\mathrm{y}}$ fell $42.3 \%$ and the load at the proportional limit $\mathrm{F}_{\mathrm{p}}$ decreased $52.1 \%$. The large series of PEB submitted to $400{ }^{\circ} \mathrm{C}$ present a reduction of $23.7 \%$ in $\mathrm{P}_{\mathrm{u}}$ relative to $\mathrm{PEB}$ at room temperature, $37.2 \%$ in the load event for the displacement limit $\mathrm{F}_{\mathrm{L} / 30}, 49.9 \%$ in the load event $\mathrm{F}_{\mathrm{y}}$ and $58.2 \%$ in the load limit $\mathrm{F}_{\mathrm{p}}$.

The deformed mode shape for PEB submitted to $400{ }^{\circ} \mathrm{C}$ was lateral torsional buckling.

PEB subjected to $600{ }^{\circ} \mathrm{C}$ present a $40.5 \%$ reduction in the value of the ultimate load $\mathrm{P}_{\mathrm{u}}, 64.9 \%$ reduction in the load event for the displacement limit $\mathrm{F}_{\mathrm{L} / 30}, 70 \%$ reduction on the yield force $\mathrm{F}_{\mathrm{y}}$ and $84.9 \%$ reduction on the proportional limit force $\mathrm{F}_{\mathrm{p}}$. The deformed failure mode occurred with

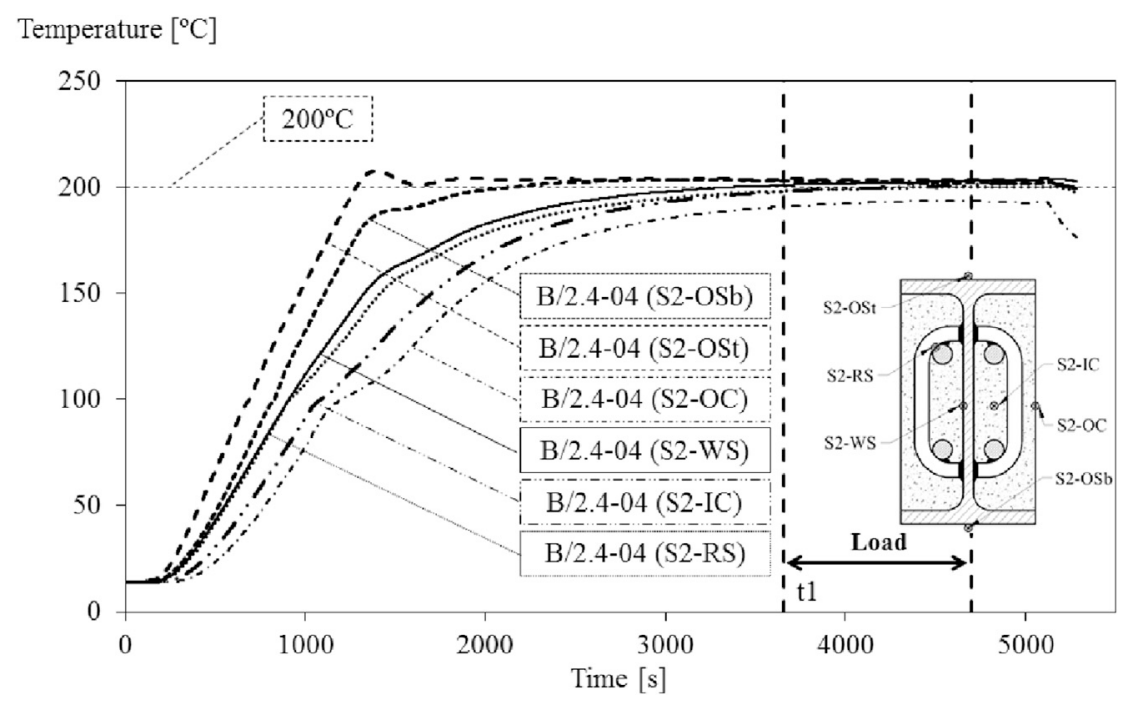

Fig. 16. Temperature evolution on section S2, for beam test B/2.4-04.

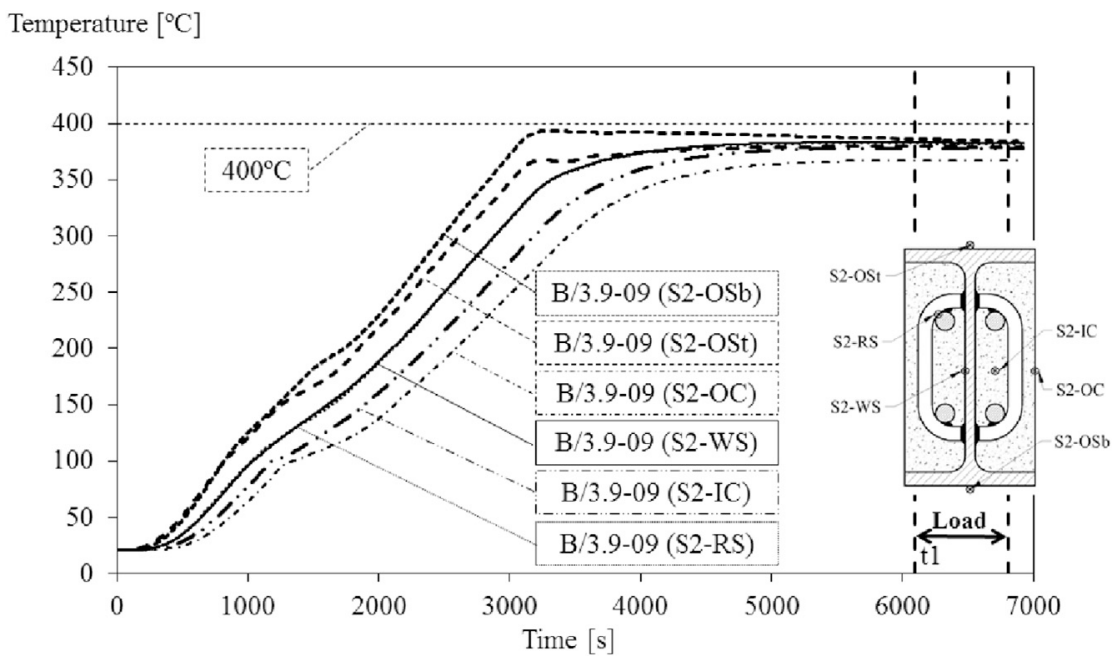

Fig. 17. Temperature evolution on section S2, for beam test B/3.9-01. 
Temperature $\left[{ }^{\circ} \mathrm{C}\right]$

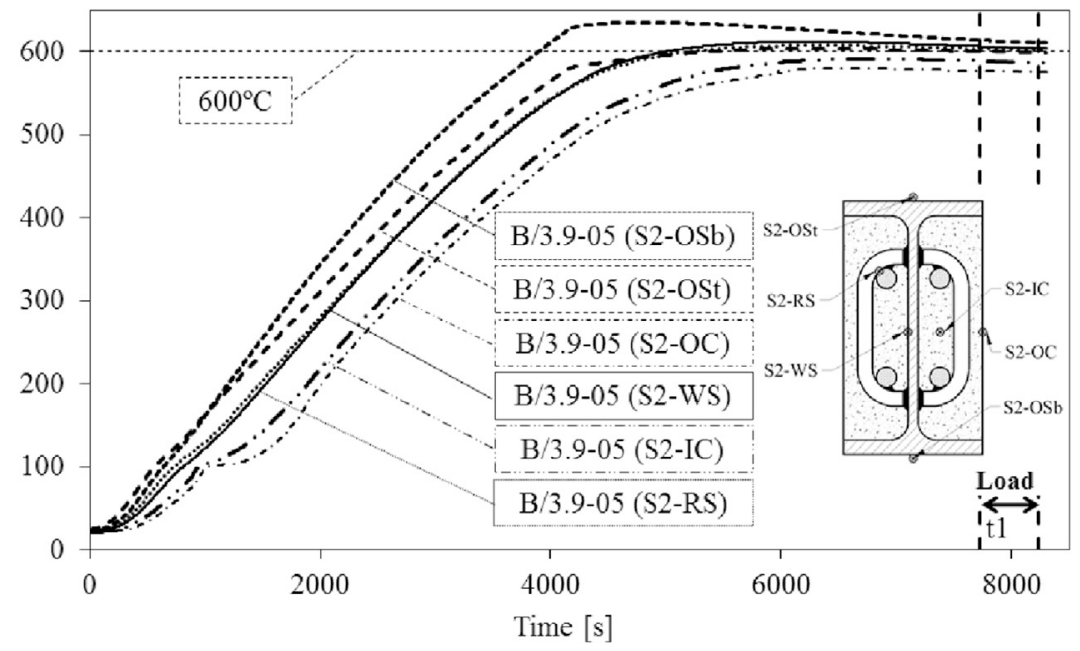

Fig. 18. Temperature evolution on section S2, for beam test B/3.9-05.

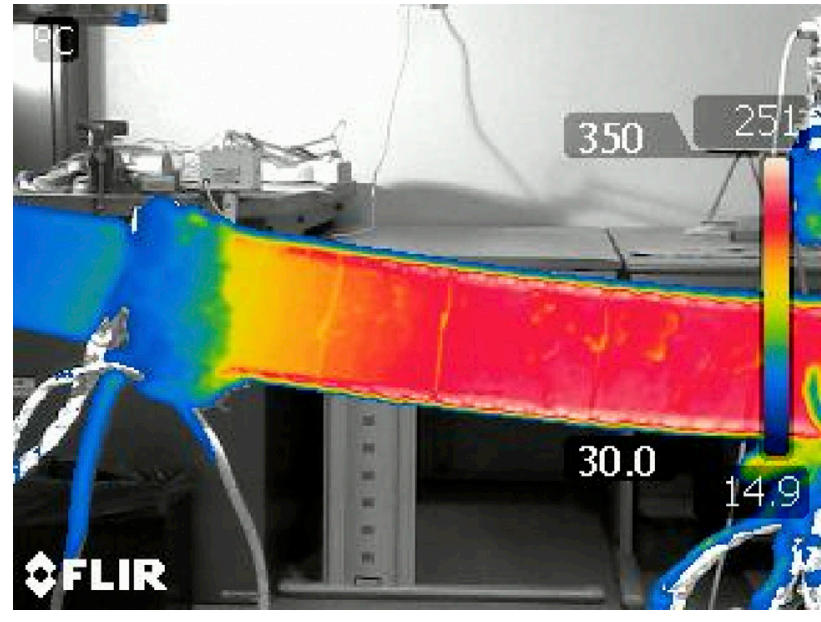

Fig. 19. Temperature gradient near section S3A, for specimen $B / 2.4-04$.

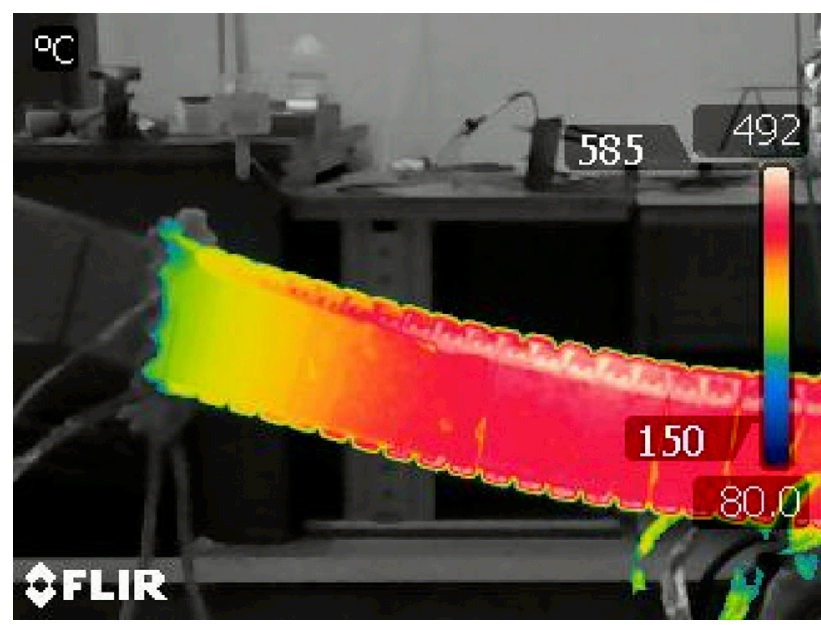

Fig. 20. Temperature gradient near section S3A, for specimen B/3.9-01.

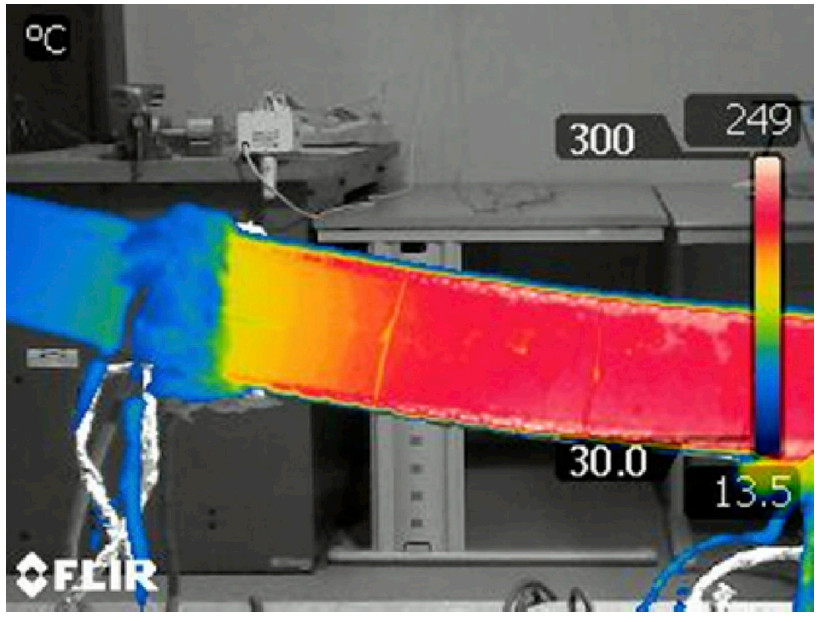

Fig. 21. Temperature gradient near section S3A, for specimen B/3.9-05.

the formation of a plastic hinge.

Typical load versus lateral displacement of PEB at elevated temperature are depicted in Figs. 27 and 28. Both series present similar results with exception to those tested at $600{ }^{\circ} \mathrm{C}$. The specimens of series 7 do not present significant lateral displacement. All other series present significant lateral displacement followed by a decrease of load, after reaching the ultimate load $\mathrm{P}_{\mathrm{u}}$. The average of the ultimate load is also presented on both graphs.

The shear effect of stirrups into the bending resistance of PEB was also analysed. Two series were dedicated to evaluate the shear effect of stirrups, considering stirrups welded to the web of the steel beam (W) and stirrups not welded (NW). Both tests were developed into different beam lengths (medium and large series) and performed at $400{ }^{\circ} \mathrm{C}$. The temperature evolution is very similar to other specimens. The type of connection between stirrups and the web (W versus NW) does not affect the temperature performance of the beam and the temperature evolution in all cross sections, as already shown in a previous work [24].

The vertical displacement is represented in Figs. 29 and 30 for both length series. The beams with stirrups not welded to the web of the beam present similar load event $\mathrm{F}_{\mathrm{L} / 30}$ when compared to beams with welded stirrups. The same type of behaviour was verified for both length series (medium and large). 


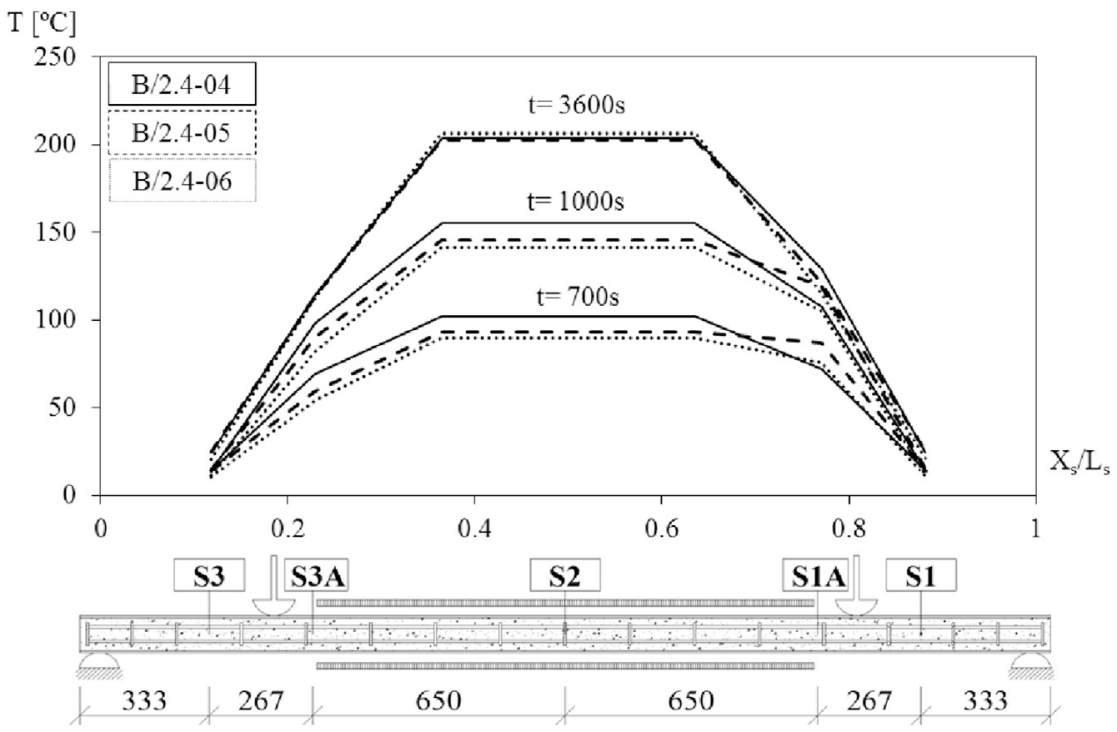

Fig. 22. Temperature profile of the beam tests series 2 .

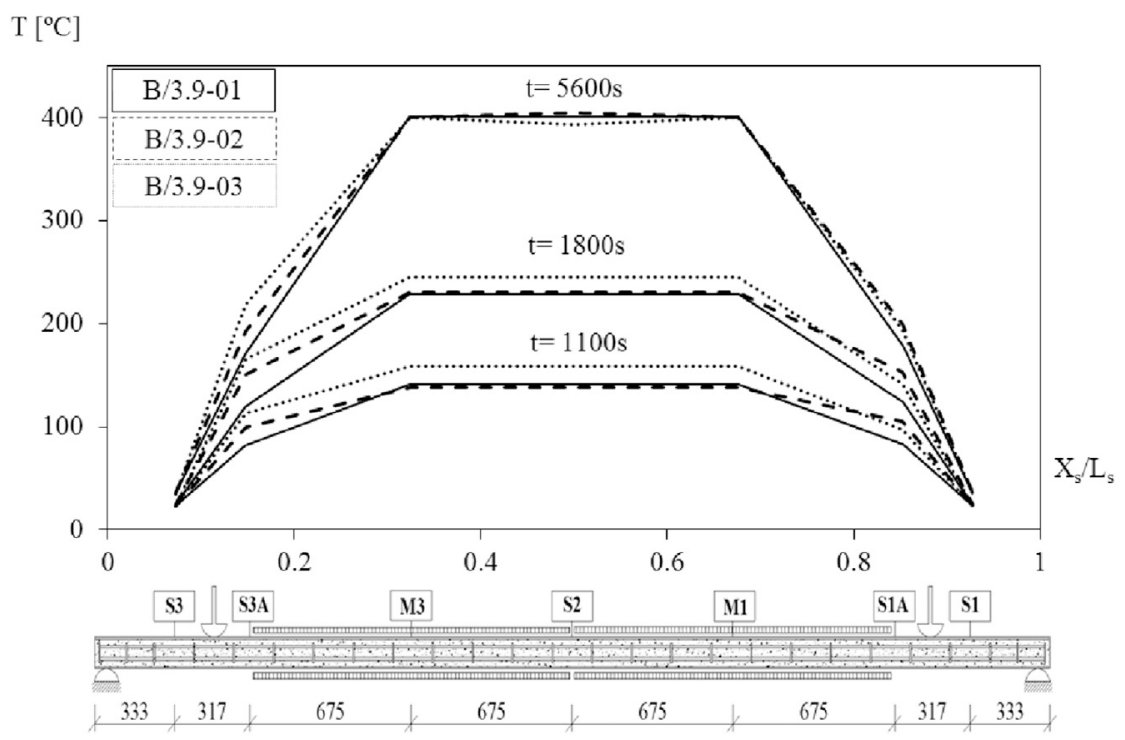

Fig. 23. Temperature profile of the beam tests series 6 .

There is no significant difference in bending resistance and stiffness. The high degree of confinement of the concrete and the dimension of the cross section (IPE100) promotes the steel-concrete bond contact, which is responsible for this similar behaviour.

Table 6 represents the main load events during tests. For the medium length series the maximum difference in any load event is smaller than $1 \%$, while for the large length series the maximum difference is smaller than $5.6 \%$.

All tested beam with welded and not welded stirrups attained the same deformed mode shape (LTB), generating similar graphical results for lateral displacement and cross section rotation. The ultimate load is similar for both conditions and for medium and large series.

\section{Analysis of results: comparison with simple calculation method}

The experimental results under incremental load show that PEB will first deflect downwards, and when the load exceeds a specific value, it moves sideways and rotate about the longitudinal axis due to instability of the compression flange. This behaviour is in some extent different from bare steel beam, because in this case beams deflect and twist out of the plane of loading from the early beginning of the loaded beam. The main characteristic of LTB is that the entire cross section rotates as a rigid cross section without distortion. Concrete reached failure by cracking and crushing, due to the applied bending moment. Similar crack patterns were observed in all tested PEB. The pattern of cracks associated with the low heating rate and the high permeability of the concrete, justify the absence of explosive concrete spalling. Local buckling of the reinforcement was also observed for the medium length specimens.

The reduction of the bending resistance of PEB series 1, 6 and 7, $M_{b, f i, t, R d} / M_{b, R d}$ (specimens submitted to $400{ }^{\circ} \mathrm{C}$ and $600{ }^{\circ} \mathrm{C}$ ) based on the simplified method, adapted from Eurocode EN1993-1-2 [14], are properly adjusted to the experimental reduction factor $\bar{X}_{F_{L / 30, \theta}} / \bar{X}_{F_{L / 30}}$, when considering the load event for the displacement limit $\mathrm{F}_{\mathrm{L} / 30}$. The reduction of the bending resistance at $200^{\circ} \mathrm{C}$ on series 2, using Eurocode 
T $\left[{ }^{\circ} \mathrm{C}\right]$

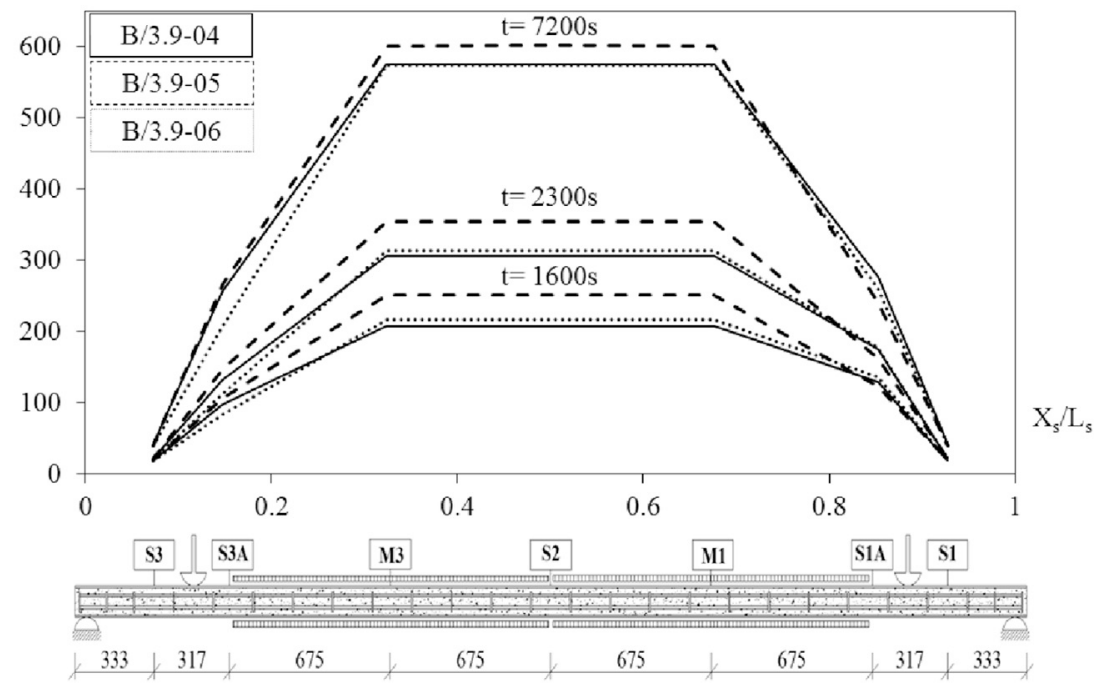

Fig. 24. Temperature profile of the beam tests series 7 .

Load $[\mathrm{N}]$

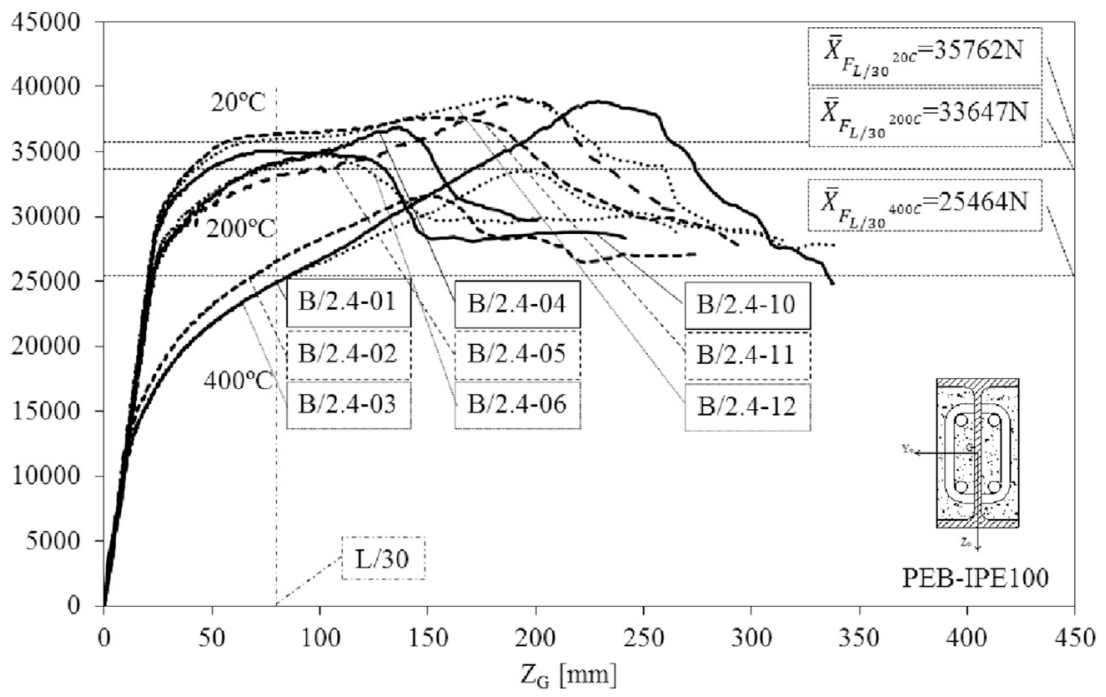

Fig. 25. Vertical displacement on PEB series 1-2-4.

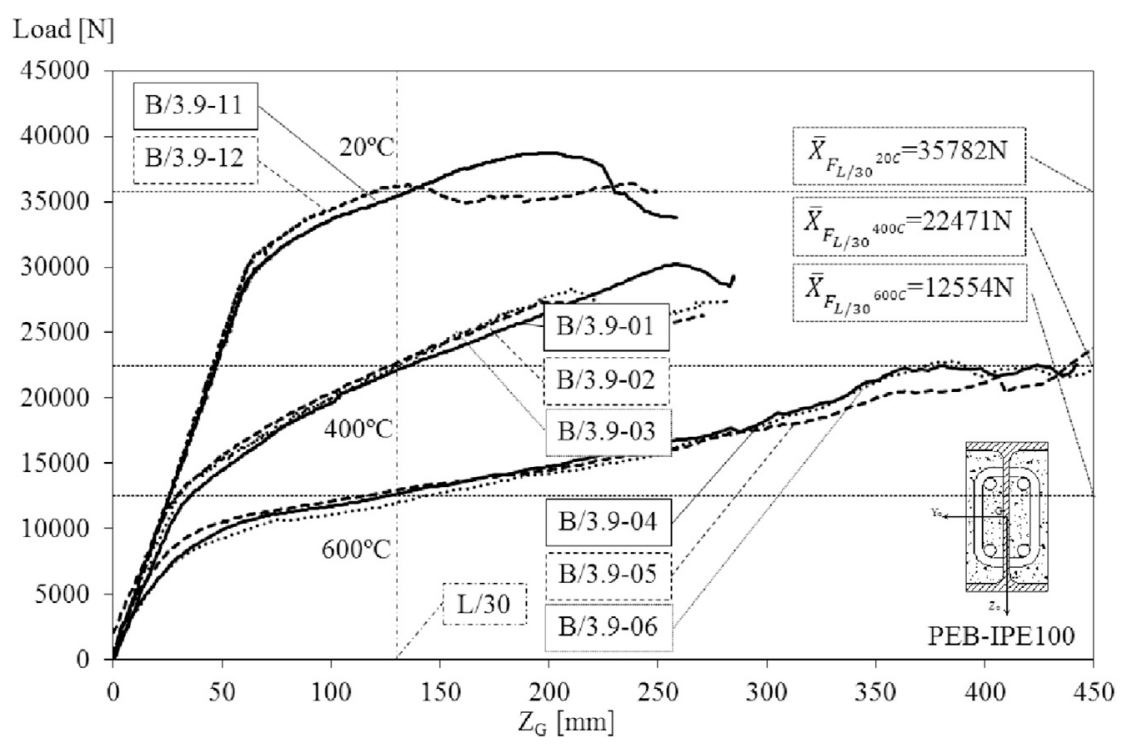

Fig. 26. Vertical displacement on PEB series 6-7-9. 
Table 5

Main load events to bending resistance on PEB series 1-2-4 and 6-7-9.

\begin{tabular}{llllll}
\hline Series & Temperature & $\bar{X}_{P_{u}}[\mathrm{~N}]$ & $\bar{X}_{F_{L / 30}}[\mathrm{~N}]$ & $\bar{X}_{F_{y}}[\mathrm{~N}]$ & $\bar{X}_{F_{p}}[\mathrm{~N}]$ \\
\hline 1 & $400{ }^{\circ} \mathrm{C}$ & 34655 & 25464 & 20190 & 12692 \\
2 & $200{ }^{\circ} \mathrm{C}$ & 36876 & 33648 & 31053 & 25793 \\
4 & Room & 37295 & 36161 & 35008 & 26537 \\
\hline 6 & $400{ }^{\circ} \mathrm{C}$ & 28610 & 22471 & 15860 & 11603 \\
7 & $600{ }^{\circ} \mathrm{C}$ & 22296 & 12554 & 9493 & 4187 \\
9 & Room & 37491 & 35782 & 31680 & 27760 \\
\hline
\end{tabular}

underestimates the bending resistance when using any of the load events $\mathrm{P}_{\mathrm{u}}, \mathrm{F}_{\mathrm{L} / 30}, \mathrm{~F}_{\mathrm{y}}$ or $\mathrm{F}_{\mathrm{p}}$, see Table 7 .

Figs. 31 and 32 represents the comparison between experimental results and the simplified calculation method adapted from Eurocode EN1993-1-2 [14]. The analytical reduction factor for the bending resistance of PEB at elevated temperature is properly adjusted to the experimental reduction factor of the tests, when considering the main load event $\mathrm{F}_{\mathrm{y}}$ during experiments.

\section{Conclusions}

This paper has presented the bending performance of twenty seven beams at different temperature levels (room, $200^{\circ} \mathrm{C}, 400^{\circ} \mathrm{C}$, and $600^{\circ} \mathrm{C}$ ), using the setup of four-point bending test. Tests consider only one cross section type (one steel section and one type of concrete), two beam lengths and two different shear conditions for stirrups. The performance of PEB was also compared to bare steel I beam, at room temperature.

Experimental measurements confirmed that temperature is not constant over the heating length, presenting strong gradients at the extremities of the heating length. This can explain an over prediction of experimental bending resistance in comparison to the simple calculation method, adapted from Eurocode.

Progressive damage of concrete occurred during experiments. Normal cracks due to tensile stress were the most visible ones, while crushing of concrete occurred due to developing of compressive stress and failure mode shape.

The bending resistance of the PEB, at room temperature, is higher than the bending resistance of bare steel beam. The reduction on bending

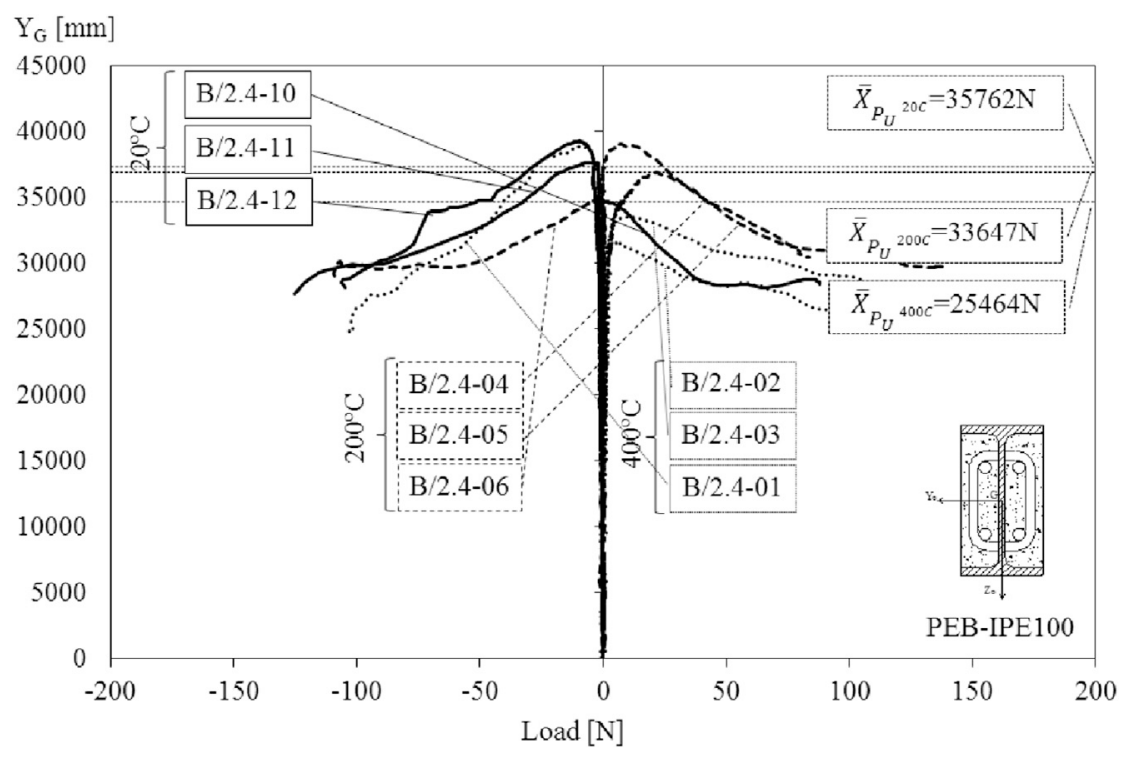

Fig. 27. Lateral displacement on PEB series 1-2-4.

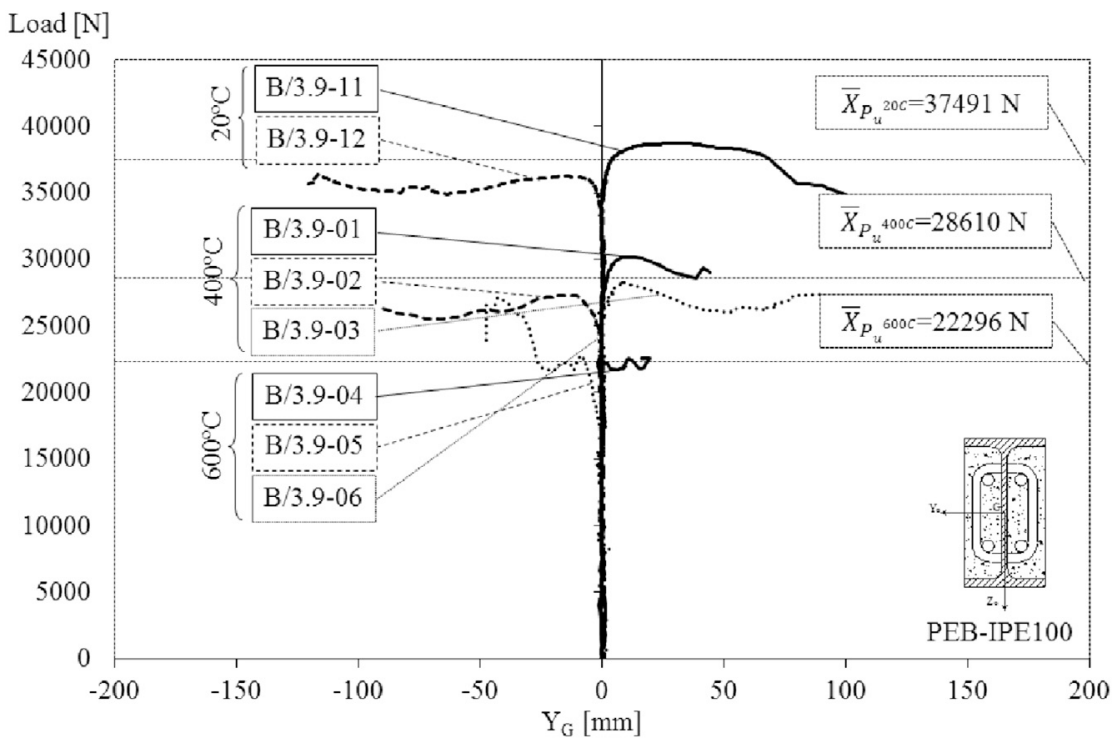

Fig. 28. Lateral displacement on PEB series 6-7-9. 


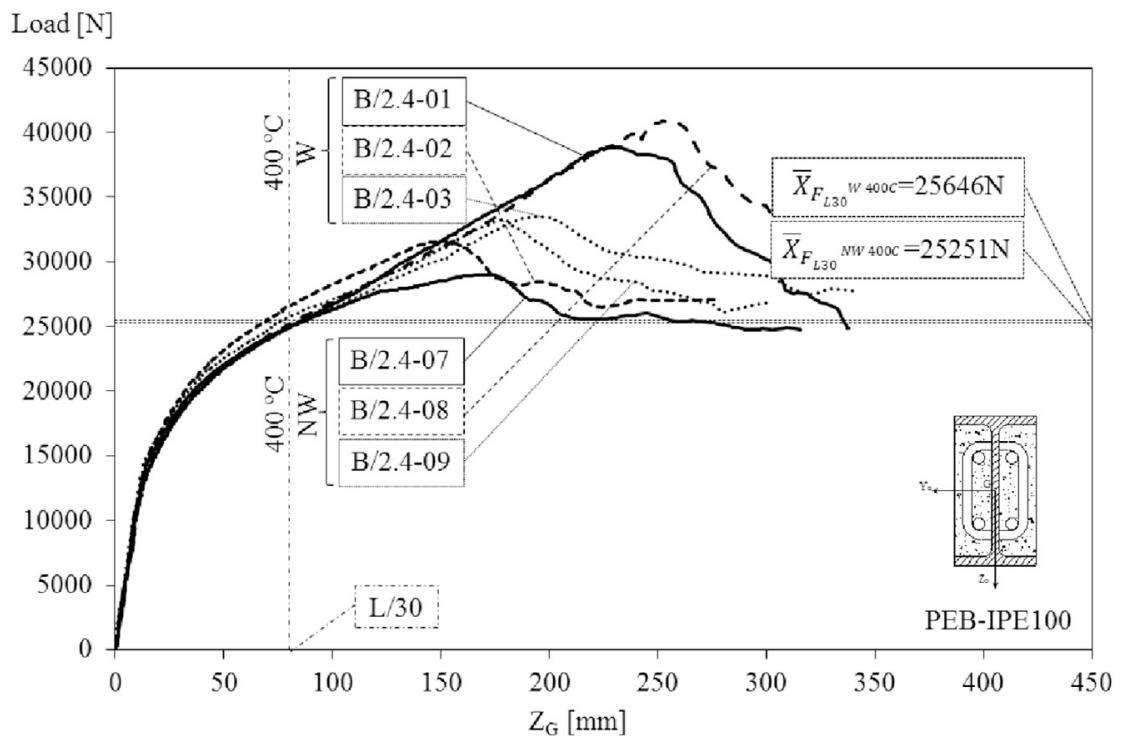

Fig. 29. Vertical displacement on PEB series 1 and 3.

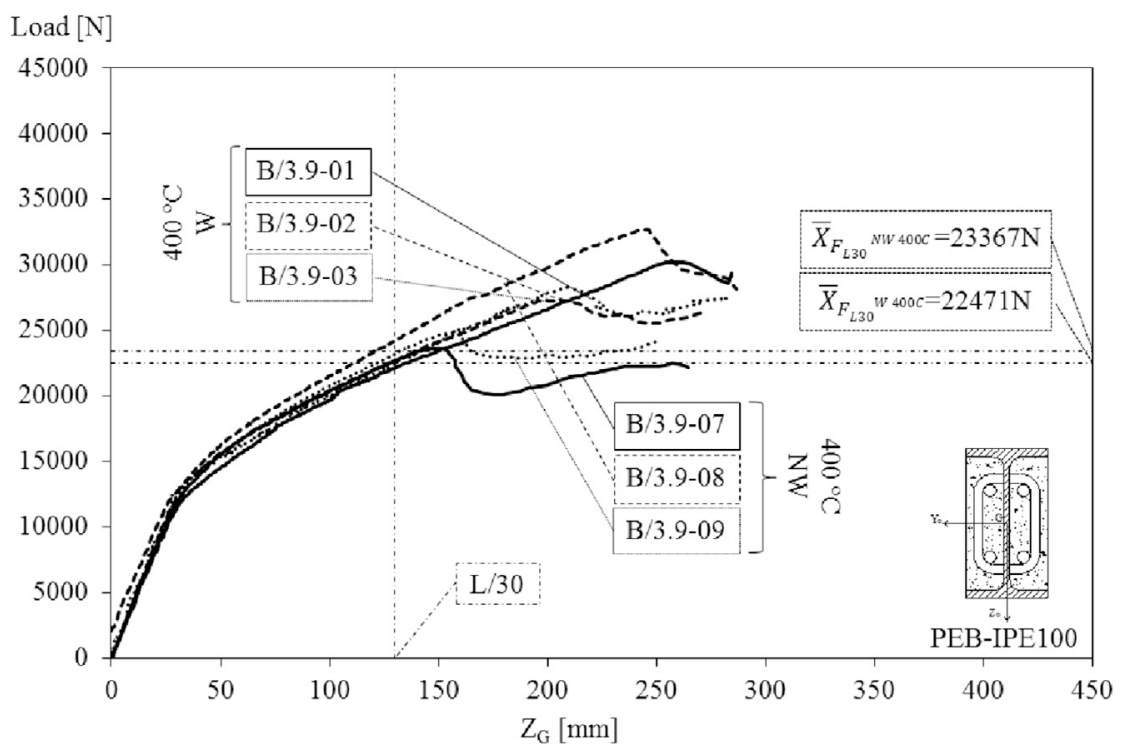

Fig. 30. Vertical displacement on PEB series 6 and 8.

Table 6

Main load events to average bending resistance on PEB series 1,3,6 and 8 .

\begin{tabular}{lllllll}
\hline Series & Temperature & Stirrups & $\bar{X}_{P_{u}}[\mathrm{~N}]$ & $\bar{X}_{F_{L / 30}}[\mathrm{~N}]$ & $\bar{X}_{F_{y}}[\mathrm{~N}]$ & $\bar{X}_{F_{p}}[\mathrm{~N}]$ \\
\hline 1 & $400{ }^{\circ} \mathrm{C}$ & $\mathrm{W}$ & 34655 & 25464 & 20190 & 12692 \\
3 & $400{ }^{\circ} \mathrm{C}$ & $\mathrm{NW}$ & 34369 & 25251 & 20243 & 12643 \\
\hline 6 & $400{ }^{\circ} \mathrm{C}$ & $\mathrm{W}$ & 28610 & 22471 & 15860 & 11603 \\
8 & $400{ }^{\circ} \mathrm{C}$ & $\mathrm{NW}$ & 27016 & 23367 & 15733 & 11683 \\
\hline
\end{tabular}

resistance of $\mathrm{PEB}$ is not directly proportional to the increase of temperature. The bending behaviour of PEB at $200{ }^{\circ} \mathrm{C}$ is quite similar to the behaviour at room temperature. An increase of temperature from $200{ }^{\circ} \mathrm{C}$ to $400{ }^{\circ} \mathrm{C}$ caused a reduction of $24 \%$ on the load event $\mathrm{F}_{\mathrm{L} / 30}$ for medium series, while an increase of temperature from room to $400{ }^{\circ} \mathrm{C}$ and to $600{ }^{\circ} \mathrm{C}$ caused a reduction of $37 \%$ and $64 \%$ on the load event of $\mathrm{F}_{\mathrm{L} / 30}$, respectively. Although the strength of PEB is not proportional to the strength of material, the reduction coefficient of the yielding stress of steel is reduced by $53 \%$ at $600{ }^{\circ} \mathrm{C}$.

The deformed failure mode was identified as lateral torsional buckling for all tested PEB and bare steel beams, with exception to those tested at $600{ }^{\circ} \mathrm{C}$, presenting plastic hinge formation, with no susceptibility to lateral torsional buckling.

The bending stiffness of $\mathrm{PEB}$, at room temperature, is $15 \%$ higher than the bending stiffness of bare steel beam, verified for both, medium and large series.

The post buckling deformation of bare steel beams is quite different from PEB. Bare steel beams presented a decrease of load after reaching the ultimate load and a bigger cross section rotation.

The bending behaviour of PEB without welded stirrups (NW) is very similar to the behaviour of PEB with welded stirrups (W), due to the dimension of the cross section of the specimens.

The concrete is responsible to an increase of $20 \%$ and $75 \%$ in the lateral torsional buckling resistance of PEB with respect to bare steel beam, as demonstrated at room temperature conditions. 
Table 7

Bending resistance on PEB series 1-2-6-7 at elevated temperature with reduction factors to room temperature.

\begin{tabular}{|c|c|c|c|c|c|c|}
\hline Series & Temperature & $\begin{array}{l}\bar{X}_{P_{u, \theta}} / \bar{X}_{P_{u}} \\
\text { (experimental) }\end{array}$ & $\begin{array}{l}\bar{X}_{F_{L / 30, \theta}} / \bar{X}_{F_{L / 30}} \\
\text { (experimental) }\end{array}$ & $\begin{array}{l}\bar{X}_{F_{y, \theta}} / \bar{X}_{F_{y}} \\
\text { (experimental) }\end{array}$ & $\begin{array}{l}\bar{X}_{F_{p, \theta}} / \bar{X}_{F_{p}} \\
\text { (experimental) }\end{array}$ & $\begin{array}{l}M_{b, f i t, R d} / M_{b, R d} \\
\text { (Simplified method) }\end{array}$ \\
\hline 2 & $200\left[{ }^{\circ} \mathrm{C}\right]$ & 0.99 & 0.93 & 0.89 & 0.97 & 0.72 \\
\hline 1 & $400\left[{ }^{\circ} \mathrm{C}\right]$ & 0.93 & 0.70 & 0.58 & 0.48 & 0.64 \\
\hline 6 & $400\left[{ }^{\circ} \mathrm{C}\right]$ & 0.76 & 0.63 & 0.50 & 0.42 & 0.49 \\
\hline 7 & $600\left[{ }^{\circ} \mathrm{C}\right]$ & 0.60 & 0.35 & 0.30 & 0.15 & 0.20 \\
\hline
\end{tabular}

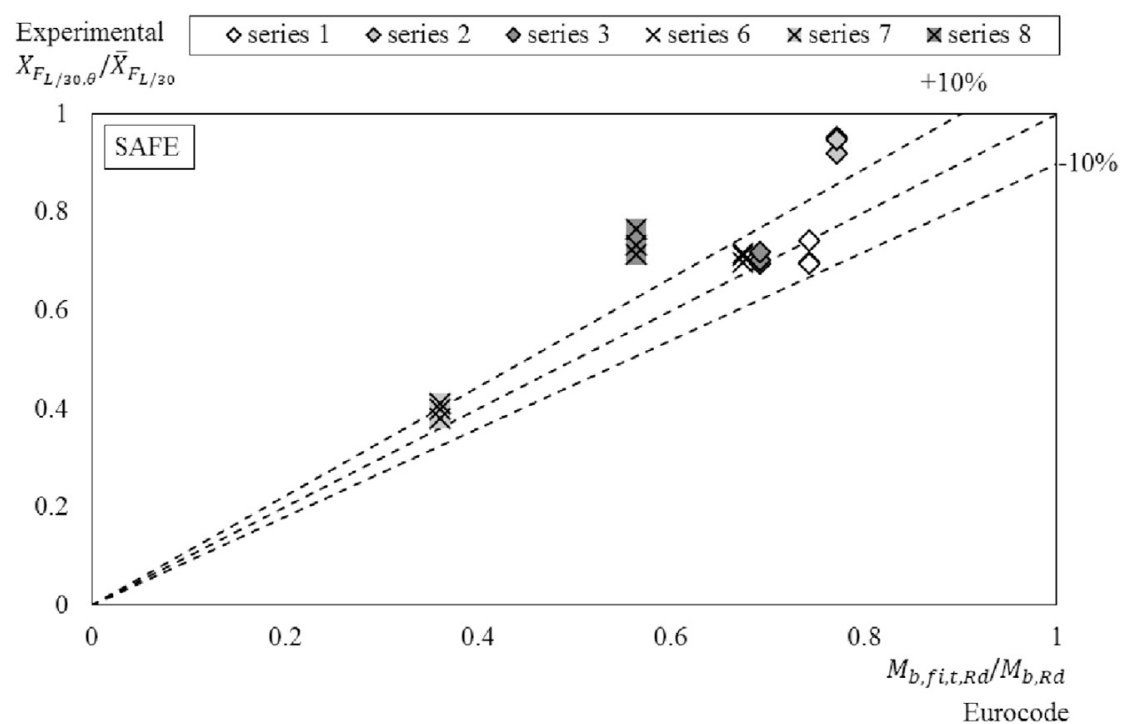

Fig. 31. Comparison between experimental results $\left(\mathrm{F}_{\mathrm{L} / 30}\right)$ and Eurocode.

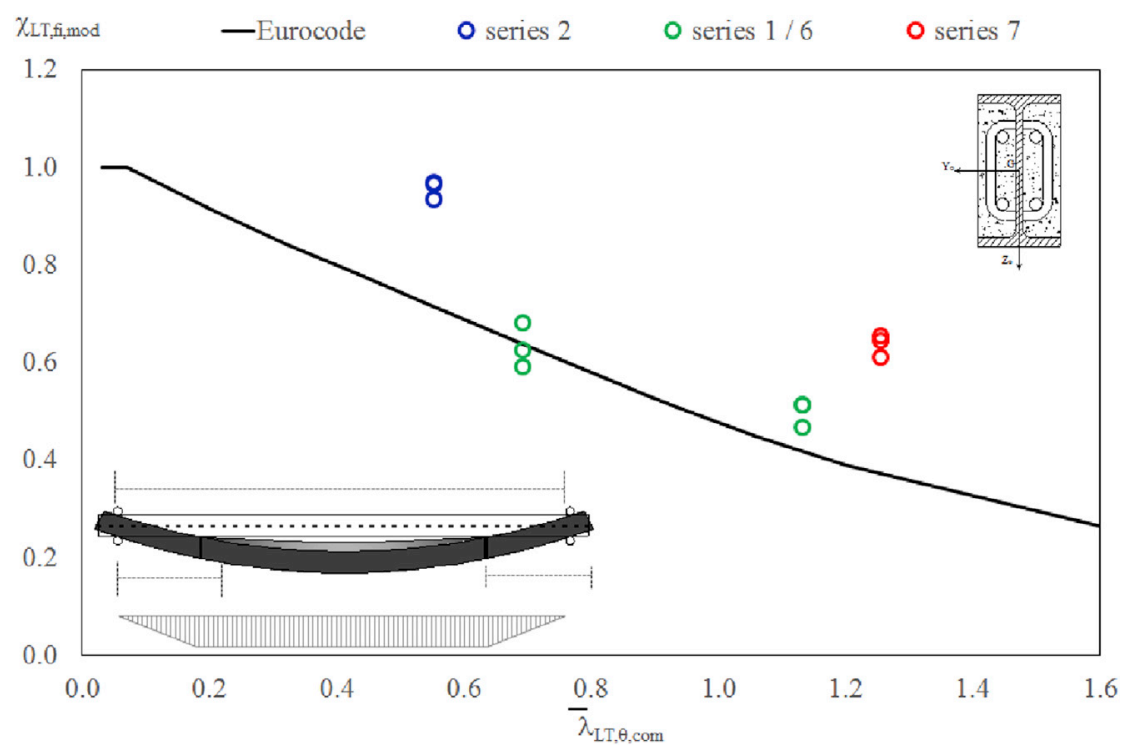

Fig. 32. Comparison between experimental results $\left(\mathrm{F}_{\mathrm{y}}\right)$ and Eurocode.

Eurocode 4, part 1.2 [13] doesn't assumes the lateral torsional buckling failure mode of Partially Encased Beams. This research proves that this requirement should be included for the structural design of composite steel and concrete buildings exposed to fire.

Experimental results were compared with the results of the simple calculation method, adapted from Eurocode EN1993-1-2 [14], concluding that this standard presents conservative results in the majority of the cases and unsafe results in very few cases (series 1 ).

Further work may be required to generalize the findings, using other PEB cross sections, lengths and temperature levels. More tests are required to verify the behaviour of different cross sections and slenderness of PEB. Also a numerical validation in on going and future developments are expected.

\section{Acknowledgements}

Authors acknowledge material support to the following companies and institutions: Arcelor - Mittal (Spain), J. Soares Correia (Portugal), Fepronor (Portugal), Hierros Furquet (Spain) and D. Samuel Solorzano Barruso Memorial Foundation-University of Salamanca (Spain). 


\section{References}

[1] Paulo A.G. Piloto, Ana B.R. Gavilán, Marco Zipponi, Alberto Marini, Luís M.R. Mesquita, Giovanni Plizzari, Experimental investigation of the fire resistance of partially encased beams, J. Constr. Steel Res. 80 (2013) 121-137.

[2] J.B. Schleich, Computer Assisted Analysis of the Fire Resistance of Steel and Composite Concrete-steel Structures (REFAO-cafir), Commission of the European Communities, Luxembourg, 1987.

[3] K. Kordina, Behaviour of composite columns and girders in fire, in: Fire Safety Science-proceedings of the Second International Symposium, International Association for Fire Safety Science, Tokyo, Japan, 1989.

[4] R. Kindmann, R. Bergmann, L.-G. Cajot, J.B. Scleich, Effect of reinforced concrete between the flanges of the steel profile of partially encased composite beam, J. Constr. Steel Res. 27 (1993) 107-122.

[5] D. Hosser, T. Dorn, O. El-Nesr, Experimental and numerical studies of composite beams exposed to fire, J. Struct. Eng. 120 (10) (1994) 2871-2892.

[6] Lindner Joachim, Budassis Nikos, Lateral torsional buckling of partially encased composite beams without concrete slab, in: Composite Construction in Steel and Concrete IV, 2000, pp. 117-128. Conference Proceedings, May 28th to June 2nd, Banff, Alberta, Canada.

[7] R. Maquoi, C. Heck, V. Ville de Goyet, Lateral Torsional Buckling in Steel and Composite Beams. Book 1, 2 and 3, Technical Steel Research Final Report EUR 20888 EN. European Commission 92-894-6414-3, August 2002.

[8] I.M. Assi, S.M. Abed, Y.M. Hunaiti, Flexural strength of composite beams partially encased in lightweight concrete, Pak J. Appl. Sci. 2 (3) (2002) 320-323.

[9] S. Nakamura, N. Narita, Bending and shear strengths of partially encased composite I-girders, J. Constr. Steel Res. 59 (2003) 1435-1453.

[10] Kodaira Akio, Fujinaka Hideo, Ohashi Hirokazu, Nishimura Toshihiko, Fire resistance of composite beams composed of rolled steel profile concreted between flanges, Fire Sci. Technol. 23 (3) (2004) 192-208.

[11] A.Y. Elghazouli, J. Treadway, Inelastic behaviour of composite members under combined bending and axial loading, J. Constr. Steel Res. 64 (2008) 1008-1019.

[12] de Nardin Silvana, H.C. El Debs Ana Lucia, Study of partially encased composite beams with innovative position of stud bolts, J. Constr. Steel Res. 65 (2) (February 2009) 342-350.
[13] CEN- EN 1994-1-2, Eurocode 4: Design of Composite Steel and Concrete Structures Part 1-2: General Rules - structural Fire Design, CEN (European Committee for Standardization), Brussels, August 2005.

[14] CEN- EN 1993-1-2, Eurocode 3: Design of Steel Structures - Part 1-2: General Rules Structural Fire Design, CEN (European Committee for Standardization), Brussels, April 2005.

[15] CEN- EN 1994-1-1, Eurocode 4: Design of Composite Steel and Concrete Structures Part 1-1: General Rules and Rules for Buildings, CEN (European Committee for Standardization), Brussels, December 2004.

[16] CEN- EN 1993-1-1, Eurocode 3: Design of Steel Structures - Part 1-1: General Rules and Rules for Buildings, CEN (European Committee for Standardization), Brussels, May 2005.

[17] N. Trahair, Flexural-torsinoal Buckling of Structures, E\&FN Spon, 1993.

[18] P.M.M. Vila Real, N. Lopes, L. Simões da Silva, J.-M. Franssen, Lateral-torsional buckling of unrestrained steel beams under fire conditions: improvement of EC3 proposal, Comput. Struct. 82 (20-21) (2004) 1737-1744.

[19] ISO TC 164, ISO 6892-1, Metallic Materials - Tensile Testing - Part 1: Method of Test at Room Temperature, International Standard, Switzerland, 2009.

[20] IPQ (Instituto Português da Qualidade), NP EN 12390-3, Ensaios do betão endurecido. Parte 3: Resistência à compressão de provetes, 2003 (in Portuguese).

[21] IPQ (Instituto Português da Qualidade), NP EN 933-1, Tests for Geometrical Properties of Aggregates — Part 1; Determination of Particle Size Distribution, Sieving Method, 2000 (in Portuguese).

[22] Wu Keru, Chen Bing, Yao Wu, Study of the influence of aggregate size distribution on mechanical properties of concrete by acoustic emission technique, Cem. Concr. Res. 31 (6) (May 2001) 919-923.

[23] P.M.M. Vila Real, P.A.G. Piloto, J.-M. Franssen, A new proposal of a simple model for the lateral-torsional buckling of unrestrained steel I-beams in case of fire: experimental and numerical validation, J. Constr. Steel Res. 59 (2) (February 2003) 179-199.

[24] Ana Belén Ramos-Gavilán, PhD thesis in Mechanical Engineering, Experimental and Numerical Study of the Bending Behaviour of Partially Encased Beams at Elevated Temperatures, vol. 13, University of Salamanca (in Spanish), November 2015. 